\title{
In vitro antitumor and antiviral activities of new benzothiazole and 1,3,4-oxadiazole-2-thione derivatives
}

\author{
TASHFEEN AKHTAR \\ SHAHID HAMEED ${ }^{1, *}$ \\ NAJIM A. AL-MASOUDI ${ }^{2, *}$ \\ ROBERTA LODDO ${ }^{3}$ \\ PAOLO LA COLLA ${ }^{3}$ \\ 1 Department of Chemistry \\ Quaid-I-Azam University \\ Islamabad-45320, Pakistan \\ ${ }^{2}$ Fachbereich Chemie Universität \\ Konstanz Postfach 5560, D-78457 \\ Konstanz Germany (formerly) \\ 3 Department of Biomedical Sciences \\ and Technologies, University of \\ Cagliari Cittadella Universitaria \\ 09042 Monserrato (CA), Italy
}

\begin{abstract}
A series of new benzothiazole derivatives $\mathbf{6 a - h}$ have been synthesized, in five steps, from substituted phenols via the 1,3,4-oxadiazole-2-thiones $\mathbf{5 a - h}$. The in vitro antitumor activity of the compounds obtained was investigated and the benzothiazol derivatives $\mathbf{6 d}$ and $\mathbf{6 e}$ showed strong effects on leukaemia cell lines CCRF-CEM $\left(C_{50}=\right.$ $12 \pm 2 \mu \mathrm{mol} \mathrm{L}^{-1}, 8 \pm 1 \mu \mathrm{mol} \mathrm{L}{ }^{-1}$, respectively). These compounds are leading candidates for further development. The title compounds were tested against representatives of several virus families containing single stranded RNA genomes, either positive-sense (ssRNA+), or negative-sense (RNA-), and against double-stranded RNA genomes (dsRNA), as well as some Flaviviridae viruses.
\end{abstract}

Keywords: 1,3,4-oxathiazoles, substituted benzothiazoles, antitumor activity, antiviral activity

Accepted April 16, 2008

A series of potent and selective antitumor agents, mostly from substituted 2-(4-aminophenyl)benzothiazoles, were developed and comprised a novel class of antitumor active compounds, especially against sensitive breast tumor cell lines, e.g., MCF-7 and MDA 468 and extended to certain colon, lung, melanoma, renal, and ovarian tumor cell lines $(1,2)$. Pyrimido benzothiazole and benzothiazolo quinoline derivatives (3), imidazo benzothiazoles (4) as well as polymerized benzothiazoles (5) showed remarkable antitumor activity. Caleta et al. (6) have synthesized several derivatives of substituted benzothiazoles; some exhibited potential cytotoxic activities against malignant cell lines.

The aryl amines, 2-(4-amino-3-methylphenyl)benzothiazole (1-3, 7), 4-(5-flurobenzo [d]thiazol-2-yl)-2-methylaniline (5F 203) (8) and 2-(3,4-dimethoxyphenyl)-5-fluoro-benzothiazole (9) are considered to be potent ligands for the aryl hydrocarbon receptor (AhR) which translocates with the drug to cell nuclei. A further class of benzothiazoles have been synthesized and exhibited potent antitumor activity, e.g., benzothiazole-substituted

\footnotetext{
*Correspondence, e-mail: shameed@qau.edu.pk; Najim.Al-Masoudi@gmx.de
} 


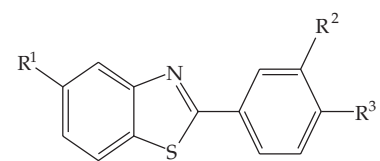

2-(4-Amino-3-methylphenyl)benzothiazole $\left(\mathrm{R}^{1}=\mathrm{H}, \mathrm{R}^{2}=\mathrm{Me}, \mathrm{R}^{3}=\mathrm{NH}_{2}\right)$

4-(5-Fluorobenzo[d]thiazol-2-yl)-2-methylaniline $\left(\mathrm{R}^{1}=\mathrm{F}, \mathrm{R}^{2}=\mathrm{Me}, \mathrm{R}^{3}=\mathrm{NH}_{2}\right)$

2-(3,4-Dimethoxyphenyl)-5-fluoro-benzothiazole $\left(\mathrm{R}^{1}=\mathrm{F}, \mathrm{R}^{2}=\mathrm{R}^{3}=\mathrm{OMe}\right)$

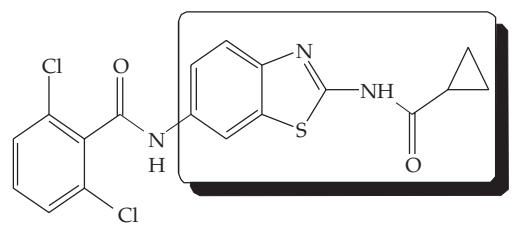

2,6-Dichloro-N-(2-(cyclopropanecarboxamido) benzo[d]thiazol-6-yl)benzamide

Scheme 1

4-hydroxycyclohexadieneone (10) against renal, colon cancer cell lines, while the antitumor benzothiazole prodrug, Phortress (11), is currently under pharmacological investigation in a phase I clinical trial in the UK. Yoshida et al. (12) synthesized a highly potent benzothiazole derivative bearing amido residue, 2,6-dichloro- $N$-(2-(cyclopropanecarboxamido)benzo[d]thiazol-6-yl)benzamide (Scheme 1) with excellent in vivo inhibitory effect on tumor growth.

On the other hand, thiazoles have also attracted great interest as anti tumour agents (13). Since varying substituents is a common method for drug design in medicinal chemistry and a useful medical value of substituted benzothiazols, such as aryl or amido groups at C-2 (Scheme 1), we aimed to synthesize new benzothiazole derivatives bearing amido-mercapto substituted 1,3,4-oxadiazoles and to investigate their antitumor and antiviral activities.

\section{EXPERIMENTAL}

Melting points were determined on melting point apparatus (Sanyo Gallenkamp, UK) and are uncorrected. IR spectra were recorded on an FTX 3000 MX BioRad Excalibar Series IR spectrophotometer, Bio Rad Laboratories (USA) using KBr pellets. ${ }^{1} \mathrm{H}$ NMR spectra were recorded on a Bruker $300 \mathrm{MHz}$ spectrometer (Germany). Mass spectra were recorded on a MAT-112-S spectrometer at $70 \mathrm{eV}$ and GCMS 5973 Inert mass selective detector, Agilent Technologies (USA); elemental analyses were performed on a CHNS-932 elemental analyzer, Leco Corporation (USA).

Analytical data for the synthesized compounds are given in Tables I and II. Synthetic routes are presented in Scheme 2.

\section{Syntheses}

General procedure for the synthesis of 4-alkyl-, 4-halo-, 3,4-dichlorophenoxyalkanoic acids $(\mathbf{1 a}-\boldsymbol{h})$. - These compounds were prepared previously in our laboratory (14) by the treatment of 2-bromopropanoic acid or 2-bromobutanoic acid with commercial substituted phenols in aqueous $\mathrm{NaOH}$. 


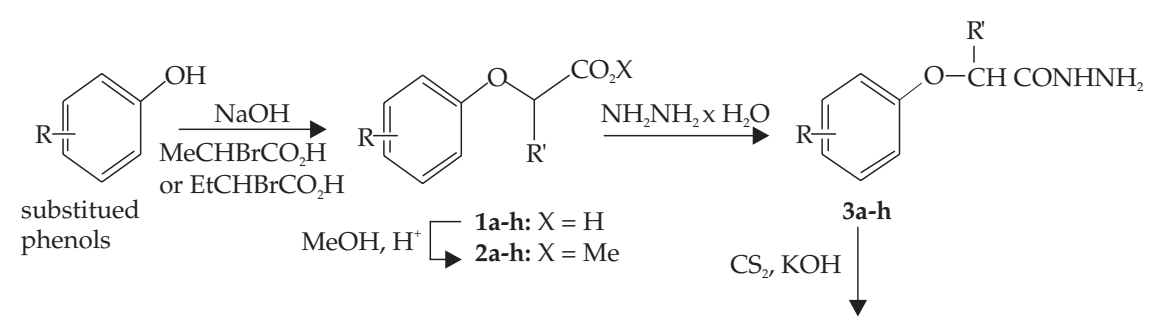<smiles>O=C(CCl)Nc1nc2ccccc2s1</smiles><smiles></smiles>

\begin{tabular}{r|ll}
$\mathbf{1 - 6}$ & $\mathrm{R}$ & $\mathrm{R}$ \\
\hline $\mathbf{a}$ & $\mathrm{Br}$ & $\mathrm{Me}$ \\
$\mathbf{b}$ & $\mathrm{Br}$ & $\mathrm{Et}$ \\
$\mathbf{c}$ & $\mathrm{Cl}$ & $\mathrm{Me}$ \\
$\mathbf{d}$ & $\mathrm{Cl}$ & $\mathrm{Et}$ \\
$\mathbf{e}$ & $3,4-\mathrm{Cl}_{2}$ & $\mathrm{Me}$ \\
$\mathbf{f}$ & $3,4-\mathrm{Cl}_{2}$ & $\mathrm{Et}$ \\
$\mathbf{g}$ & $\mathrm{Me}$ & $\mathrm{Me}$ \\
$\mathbf{h}$ & $\mathrm{Me}$ & $\mathrm{Et}$
\end{tabular}

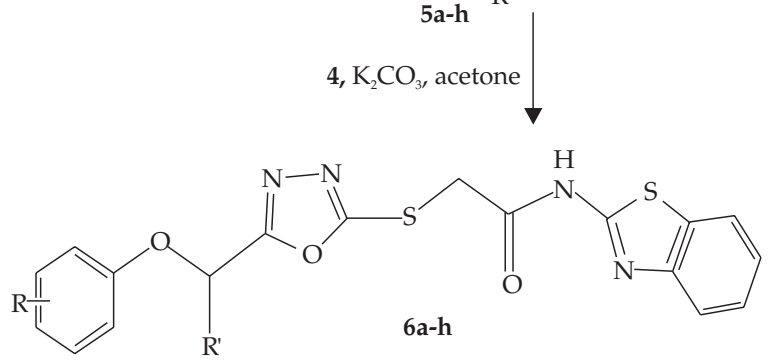

Sheme 2

Table I. Physicochemical data of the newly prepared compounds

\begin{tabular}{|c|c|c|c|c|c|c|}
\hline \multirow{2}{*}{$\begin{array}{l}\text { Compd. } \\
\text { No. }\end{array}$} & \multirow{2}{*}{$\begin{array}{c}\text { Yield } \\
(\%)\end{array}$} & \multirow{2}{*}{$\begin{array}{l}\text { M.p. } \\
\left({ }^{\circ} \mathrm{C}\right)\end{array}$} & \multirow{2}{*}{$\begin{array}{l}\text { Mol. formula } \\
\qquad\left(M_{\mathrm{r}}\right)\end{array}$} & \multicolumn{3}{|c|}{ Found/calcd. (\%) } \\
\hline & & & & C & $\mathrm{H}$ & $\mathrm{N}$ \\
\hline $3 a$ & 78 & $143-144$ & $\begin{array}{c}\mathrm{C}_{9} \mathrm{H}_{11} \mathrm{BrN}_{2} \mathrm{O}_{2} \\
(259.10)\end{array}$ & $\begin{array}{l}41.72 \\
41.56\end{array}$ & $\begin{array}{l}4.28 \\
4.19\end{array}$ & $\begin{array}{l}10.81 \\
10.69\end{array}$ \\
\hline $3 b$ & 79 & $121-123$ & $\begin{array}{c}\mathrm{C}_{10} \mathrm{H}_{13} \mathrm{BrN}_{2} \mathrm{O}_{2} \\
(273.13)\end{array}$ & $\begin{array}{l}43.97 \\
43.77\end{array}$ & $\begin{array}{l}4.80 \\
4.72\end{array}$ & $\begin{array}{l}10.26 \\
10.02\end{array}$ \\
\hline $3 c$ & 76 & $97-98$ & $\begin{array}{c}\mathrm{C}_{9} \mathrm{H}_{11} \mathrm{ClN}_{2} \mathrm{O}_{2} \\
\quad(214.65)\end{array}$ & $\begin{array}{l}50.36 \\
50.17\end{array}$ & $\begin{array}{l}5.17 \\
5.09\end{array}$ & $\begin{array}{l}13.05 \\
12.89\end{array}$ \\
\hline $3 d$ & 63 & $142-143$ & $\begin{array}{c}\mathrm{C}_{10} \mathrm{H}_{13} \mathrm{ClN}_{2} \mathrm{O}_{2} \\
(228.68)\end{array}$ & $\begin{array}{l}52.52 \\
52.37\end{array}$ & $\begin{array}{l}5.73 \\
5.64\end{array}$ & $\begin{array}{l}12.25 \\
12.07\end{array}$ \\
\hline $3 e$ & 80 & $140-141$ & $\begin{array}{c}\mathrm{C}_{9} \mathrm{H}_{10} \mathrm{Cl}_{2} \mathrm{~N}_{2} \mathrm{O}_{2} \\
(249.09)\end{array}$ & $\begin{array}{l}43.40 \\
43.21\end{array}$ & $\begin{array}{l}4.05 \\
3.98\end{array}$ & $\begin{array}{l}11.25 \\
11.22\end{array}$ \\
\hline $3 f$ & 76 & $98-99$ & $\begin{array}{c}\mathrm{C}_{10} \mathrm{H}_{12} \mathrm{ClN}_{2} \mathrm{O}_{2} \\
(263.12)\end{array}$ & $\begin{array}{l}45.65 \\
45.44\end{array}$ & $\begin{array}{l}4.60 \\
4.54\end{array}$ & $\begin{array}{l}10.65 \\
10.43\end{array}$ \\
\hline $3 g$ & 93 & $70-71$ & $\begin{array}{c}\mathrm{C}_{10} \mathrm{H}_{14} \mathrm{~N}_{2} \mathrm{O}_{2} \\
(194.23)\end{array}$ & $\begin{array}{l}61.23 \\
61.01\end{array}$ & $\begin{array}{l}7.27 \\
7.21\end{array}$ & $\begin{array}{l}14.42 \\
14.30\end{array}$ \\
\hline
\end{tabular}


T. Akhtar et al: In vitro antitumor and antiviral activities of new benzothiazole and 1,3,4-oxadiazole-2-thione derivatives, Acta Pharm. 58 (2008) 135-149.

Table I. Continuation

\begin{tabular}{|c|c|c|c|c|c|c|}
\hline \multirow{2}{*}{$\begin{array}{l}\text { Compd. } \\
\text { No. }\end{array}$} & \multirow{2}{*}{$\begin{array}{c}\text { Yield } \\
(\%)\end{array}$} & \multirow{2}{*}{$\begin{array}{l}\text { M.p. } \\
\left({ }^{\circ} \mathrm{C}\right)\end{array}$} & \multirow{2}{*}{$\begin{array}{l}\text { Mol. formula } \\
\qquad\left(M_{\mathrm{r}}\right)\end{array}$} & \multicolumn{3}{|c|}{ Found/calcd. (\%) } \\
\hline & & & & C & $\mathrm{H}$ & $\mathrm{N}$ \\
\hline $3 h$ & 80 & $56-57$ & $\begin{array}{l}\mathrm{C}_{11} \mathrm{H}_{16} \mathrm{~N}_{2} \mathrm{O}_{2} \\
(208.28)\end{array}$ & $\begin{array}{l}63.44 \\
63.23\end{array}$ & $\begin{array}{l}7.74 \\
7.67\end{array}$ & $\begin{array}{l}13.45 \\
13.27\end{array}$ \\
\hline $5 a$ & 82 & $124-125$ & $\begin{array}{c}\mathrm{C}_{10} \mathrm{H}_{9} \mathrm{BrN}_{2} \mathrm{O}_{2} \mathrm{~S} \\
(299.96)\end{array}$ & $\begin{array}{l}39.62 \\
39.88\end{array}$ & $\begin{array}{l}2.93 \\
3.01\end{array}$ & $\begin{array}{c}9.30 \\
14.30\end{array}$ \\
\hline $5 b$ & 84 & $84-86$ & $\begin{array}{c}\mathrm{C}_{11} \mathrm{H}_{11} \mathrm{BrN}_{2} \mathrm{O}_{2} \mathrm{~S} \\
(315.19)\end{array}$ & $\begin{array}{l}41.71 \\
41.92\end{array}$ & $\begin{array}{l}3.47 \\
3.52\end{array}$ & $\begin{array}{l}8.67 \\
8.89\end{array}$ \\
\hline $5 c$ & 83 & $113-114$ & $\begin{array}{c}\mathrm{C}_{10} \mathrm{H}_{9} \mathrm{ClN}_{2} \mathrm{O}_{2} \mathrm{~S} \\
(256.71)\end{array}$ & $\begin{array}{l}46.53 \\
46.79\end{array}$ & $\begin{array}{l}3.43 \\
3.53\end{array}$ & $\begin{array}{l}10.79 \\
10.91\end{array}$ \\
\hline $5 d$ & 79 & $84-86$ & $\begin{array}{c}\mathrm{C}_{11} \mathrm{H}_{11} \mathrm{ClN}_{2} \mathrm{O}_{2} \mathrm{~S} \\
(270.74)\end{array}$ & $\begin{array}{l}48.61 \\
48.80\end{array}$ & $\begin{array}{l}3.98 \\
4.10\end{array}$ & $\begin{array}{l}11.63 \\
10.35\end{array}$ \\
\hline $5 e$ & 76 & $108-110$ & $\begin{array}{c}\mathrm{C}_{10} \mathrm{H}_{8} \mathrm{Cl}_{2} \mathrm{~N}_{2} \mathrm{O}_{2} \mathrm{~S} \\
(291.15)\end{array}$ & $\begin{array}{l}40.94 \\
41.25\end{array}$ & $\begin{array}{l}2.59 \\
2.77\end{array}$ & $\begin{array}{l}9.45 \\
9.52\end{array}$ \\
\hline $5 f$ & 78 & $96-98$ & $\begin{array}{c}\mathrm{C}_{11} \mathrm{H}_{10} \mathrm{Cl}_{2} \mathrm{~N}_{2} \mathrm{O}_{2} \mathrm{~S} \\
(305.18)\end{array}$ & $\begin{array}{l}43.05 \\
43.29\end{array}$ & $\begin{array}{l}3.22 \\
3.30\end{array}$ & $\begin{array}{l}8.94 \\
9.18\end{array}$ \\
\hline $5 g$ & 67 & $86-88$ & $\begin{array}{c}\mathrm{C}_{11} \mathrm{H}_{12} \mathrm{~N}_{2} \mathrm{O}_{2} \mathrm{~S} \\
(236.29)\end{array}$ & $\begin{array}{l}55.70 \\
55.91\end{array}$ & $\begin{array}{l}5.03 \\
5.12\end{array}$ & $\begin{array}{l}11.66 \\
11.86\end{array}$ \\
\hline $5 \mathrm{~h}$ & 80 & $76-77$ & $\begin{array}{c}\mathrm{C}_{12} \mathrm{H}_{14} \mathrm{~N}_{2} \mathrm{O}_{2} \mathrm{~S} \\
(250.32)\end{array}$ & $\begin{array}{l}57.35 \\
57.58\end{array}$ & $\begin{array}{l}5.57 \\
5.64\end{array}$ & $\begin{array}{l}10.89 \\
11.19\end{array}$ \\
\hline $6 a$ & 75 & 191-192 & $\begin{array}{c}\mathrm{C}_{19} \mathrm{H}_{15} \mathrm{BrN}_{4} \mathrm{O}_{3} \mathrm{~S}_{2} \\
(491.38)\end{array}$ & $\begin{array}{l}46.77 \\
46.44\end{array}$ & $\begin{array}{l}3.04 \\
3.08\end{array}$ & $\begin{array}{l}11.53 \\
11.40\end{array}$ \\
\hline $6 b$ & 71 & $178-180$ & $\begin{array}{c}\mathrm{C}_{20} \mathrm{H}_{17} \mathrm{BrN}_{4} \mathrm{O}_{3} \mathrm{~S}_{2} \\
(505.41)\end{array}$ & $\begin{array}{l}47.33 \\
47.53\end{array}$ & $\begin{array}{l}3.31 \\
3.39\end{array}$ & $\begin{array}{l}10.89 \\
11.09\end{array}$ \\
\hline $6 c$ & 83 & $179-180$ & $\begin{array}{c}\mathrm{C}_{19} \mathrm{H}_{15} \mathrm{ClN}_{4} \mathrm{O}_{3} \mathrm{~S}_{2} \\
(446.63)\end{array}$ & $\begin{array}{l}50.83 \\
51.06\end{array}$ & $\begin{array}{l}3.42 \\
3.38\end{array}$ & $\begin{array}{l}12.37 \\
12.54\end{array}$ \\
\hline $6 d$ & 61 & $186-188$ & $\begin{array}{c}\mathrm{C}_{20} \mathrm{H}_{17} \mathrm{ClN}_{4} \mathrm{O}_{3} \mathrm{~S}_{2} \\
(460.96)\end{array}$ & $\begin{array}{l}51.92 \\
52.11\end{array}$ & $\begin{array}{l}3.85 \\
3.72\end{array}$ & $\begin{array}{l}12.23 \\
12.15\end{array}$ \\
\hline $6 e$ & 68 & 195-196 & $\begin{array}{c}\mathrm{C}_{19} \mathrm{H}_{21} \mathrm{ClN}_{4} \mathrm{O}_{2} \mathrm{~S}_{2} \\
(481.38)\end{array}$ & $\begin{array}{l}47.55 \\
52.22\end{array}$ & $\begin{array}{l}4.72 \\
4.84\end{array}$ & $\begin{array}{l}11.56 \\
12.82\end{array}$ \\
\hline $6 f$ & 56 & 197-198 & $\begin{array}{c}\mathrm{C}_{20} \mathrm{H}_{16} \mathrm{Cl}_{2} \mathrm{~N}_{4} \mathrm{O}_{3} \mathrm{~S}_{2} \\
(495.40)\end{array}$ & $\begin{array}{l}48.31 \\
48.49\end{array}$ & $\begin{array}{l}3.15 \\
4.84\end{array}$ & $\begin{array}{l}11.31 \\
11.26\end{array}$ \\
\hline $6 \mathrm{~g}$ & 74 & $205-206$ & $\begin{array}{c}\mathrm{C}_{20} \mathrm{H}_{18} \mathrm{~N}_{4} \mathrm{O}_{3} \mathrm{~S}_{2} \\
(426.51)\end{array}$ & $\begin{array}{l}55.93 \\
56.32\end{array}$ & $\begin{array}{l}4.19 \\
4.25\end{array}$ & $\begin{array}{l}13.19 \\
13.14\end{array}$ \\
\hline $6 h$ & 75 & 178-180 & $\begin{array}{c}\mathrm{C}_{21} \mathrm{H}_{20} \mathrm{~N}_{4} \mathrm{O}_{3} \mathrm{~S}_{2} \\
(440.54)\end{array}$ & $\begin{array}{l}57.05 \\
57.25\end{array}$ & $\begin{array}{l}4.64 \\
4.58\end{array}$ & $\begin{array}{l}12.76 \\
12.72\end{array}$ \\
\hline
\end{tabular}

2-(Bromophenoxy)propanoic acid (1a), 2-(bromophenoxy)butanoic acid (1b), 2-(chlorophenoxy)propanoic acid (1c), 2-(chlorophenoxy)butanoic acid (1d), 2-(3,4-dichlorophenoxy)propanoic acid (1e), 2-(3,4-dichlorophenoxy)butanoic acid (1f), 2-( $p$-tolyloxy)propanoic acid (1g), 2-( $p$-tolyloxy)butanoic acid (1h) were prepared by condensation of $p$-bromophenol with 2-bromopropanoic acid, $p$-bromophenol with 2-bromobutanoic acid, 
T. Akhtar et al.: In vitro antitumor and antiviral activities of new benzothiazole and 1,3,4-oxadiazole-2-thione derivatives, Acta Pharm. 58 (2008) 135-149.

Table II. Mass, ${ }^{1} \mathrm{H}$ and ${ }^{13} \mathrm{C}$ NMR data of the newly prepared compounds

\begin{tabular}{|c|c|c|}
\hline Compd. & Mass $(m / z)$ & ${ }^{1} \mathrm{H} \operatorname{NMR}(\delta, \mathrm{ppm})$ and ${ }^{13} \mathrm{C} \operatorname{NMR}(\delta, \mathrm{ppm})$ \\
\hline \multirow[t]{2}{*}{$3 a$} & $\begin{array}{l}260 / 261 \\
{[\mathrm{M}+\mathrm{H}]^{+}}\end{array}$ & $\begin{array}{l}1.57(3 \mathrm{H}, \mathrm{d}, J=6.5 \mathrm{~Hz}, \mathrm{OCHMe}), 3.88\left(2 \mathrm{H}, \text { br s., } \mathrm{NH}_{2}\right), 4.71(1 \mathrm{H}, \mathrm{d}, \\
J=6.5 \mathrm{~Hz}, \mathrm{OCHMe}), 6.74-6.79(2 \mathrm{H}, \mathrm{m}, \mathrm{ArH}), 7.36-7.42(2 \mathrm{H}, \mathrm{m}, \mathrm{ArH}), \\
7.75(1 \mathrm{H}, \mathrm{br} \text { s., NH})\end{array}$ \\
\hline & & $\begin{array}{l}\text { 18.6 (OCHMe), } 74.8(\mathrm{OCHMe}), 114.5\left(\mathrm{Br}_{-} \mathrm{C}_{4}-\mathrm{Ar}\right), 117.2\left(\mathrm{Br}-\mathrm{C}_{3,6}-\mathrm{Ar}\right) \\
132.7\left(\mathrm{Br}-\mathrm{C}_{3,5}-\mathrm{Ar}\right), 155.8\left(\mathrm{Ar}-\mathrm{C}_{1}-\mathrm{O}\right), 172.0(\mathrm{C}=\mathrm{O})\end{array}$ \\
\hline \multirow[t]{2}{*}{$3 b$} & $\begin{array}{l}273 / 275 \\
{[\mathrm{M}+\mathrm{H}]^{+}}\end{array}$ & $\begin{array}{l}1.02\left(\mathrm{t}, 3 \mathrm{H}, J=7.3 \mathrm{~Hz}, \mathrm{CH}_{2} \mathrm{CH}_{3}\right), 1.86-2.03\left(2 \mathrm{H}, \mathrm{m}, \mathrm{CH}_{2} \mathrm{CH}_{3}\right), 3.87 \\
\left(2 \mathrm{H}, \mathrm{br} \mathrm{s}, \mathrm{NH}_{2}\right), 4.57\left(1 \mathrm{H}, \mathrm{dd}, J=4.8 \mathrm{~Hz}, J=6.6 \mathrm{~Hz}, \mathrm{OCHCH}_{2} \mathrm{CH}_{3}\right), \\
6.77-6.80(2 \mathrm{H}, \mathrm{m}, \mathrm{ArH}), 7.38-7.41(2 \mathrm{H}, \mathrm{m}, \mathrm{ArH}), 7.60(1 \mathrm{H}, \mathrm{br} \mathrm{s}, \mathrm{NH})\end{array}$ \\
\hline & & $\begin{array}{l}\text { 9.18 }\left(\mathrm{CH}_{2} \mathrm{CH}_{3}\right), 26.0\left(\mathrm{CH}_{2} \mathrm{CH}_{3}\right), 79.7\left(\mathrm{OCHCH}_{2} \mathrm{CH}_{3}\right), 114.5\left(\mathrm{Br}-\mathrm{C}_{4}-\mathrm{Ar}\right) \\
117.2\left(\mathrm{Br}-\mathrm{C}_{2,6}-\mathrm{Ar}\right), 132.7\left(\mathrm{Br}-\mathrm{C}_{3,5}-\mathrm{Ar}\right), 156.4\left(\mathrm{Ar}^{-} \mathrm{C}_{1}-\mathrm{O}\right), 171.4(\mathrm{C}=\mathrm{O})\end{array}$ \\
\hline \multirow[t]{2}{*}{$3 c$} & $\begin{array}{l}214 / 216 \\
{[\mathrm{M}+\mathrm{H}]^{+}}\end{array}$ & $\begin{array}{l}1.58(3 \mathrm{H}, \mathrm{d}, J=6.6 \mathrm{~Hz}, \mathrm{OCHMe}), 3.87\left(2 \mathrm{H}, \text { br s., } \mathrm{NH}_{2}\right), 4.72(1 \mathrm{H}, \mathrm{d}, \\
J=6.6 \mathrm{~Hz}, \mathrm{OCHMe}), 6.80-6.85(2 \mathrm{H}, \mathrm{m}, \mathrm{ArH}), 7.23-7.29(2 \mathrm{H}, \mathrm{m}, \mathrm{ArH}), \\
7.67(1 \mathrm{H}, \mathrm{br} \mathrm{s} ., \mathrm{NH})\end{array}$ \\
\hline & & $\begin{array}{l}18.6(\mathrm{OCHMe}), 74.9(\mathrm{OCHMe}), 116.7\left(\mathrm{Cl}_{-} \mathrm{C}_{2,6}-\mathrm{Ar}\right), 127.2\left(\mathrm{Cl}-\mathrm{C}_{4}-\mathrm{Ar}\right) \\
129.8\left(\mathrm{Cl}^{-} \mathrm{C}_{3,5}-\mathrm{Ar}\right), 155.8\left(\mathrm{Ar}-\mathrm{C}_{1}-\mathrm{O}\right), 172.0(\mathrm{C}=\mathrm{O})\end{array}$ \\
\hline \multirow[t]{2}{*}{$3 d$} & $\begin{array}{l}228 / 230 \\
{[\mathrm{M}+\mathrm{H}]^{+}}\end{array}$ & $\begin{array}{l}1.02\left(3 \mathrm{H}, \mathrm{t}, J=7.3 \mathrm{~Hz}, \mathrm{CH}_{2} \mathrm{CH}_{3}\right), 1.88-2.03\left(2 \mathrm{H}, \mathrm{m}, \mathrm{CH}_{2} \mathrm{CH}_{3}\right), 3.73 \\
\left(2 \mathrm{H}, \mathrm{br} \mathrm{s} ., \mathrm{NH}_{2}\right), 4.57\left(1 \mathrm{H}, \mathrm{dd}, J=4.6 \mathrm{~Hz}, J=6.4 \mathrm{~Hz}, \mathrm{OCHCH}_{2} \mathrm{CH}_{3}\right), \\
6.81-6.86(2 \mathrm{H}, \mathrm{m}, \mathrm{ArH}), 7.23-7.28(2 \mathrm{H}, \mathrm{m}, \mathrm{ArH}), 7.62(1 \mathrm{H}, \mathrm{br} \mathrm{s} ., \mathrm{NH})\end{array}$ \\
\hline & & $\begin{array}{l}9.2\left(\mathrm{CH}_{2} \mathrm{CH}_{3}\right), 26.0\left(\mathrm{CH}_{2} \mathrm{CH}_{3}\right), 79.8\left(\mathrm{OCHCH}_{2} \mathrm{CH}_{3}\right), 116.7\left(\mathrm{Cl}-\mathrm{C}_{2,6}-\mathrm{Ar}\right), \\
127.2\left(\mathrm{Cl}-\mathrm{C}_{4}-\mathrm{Ar}\right), 129.7\left(\mathrm{Cl}-\mathrm{C}_{3,5}-\mathrm{Ar}\right), 155.8\left(\mathrm{Ar}^{-} \mathrm{C}_{1}-\mathrm{O}\right), 171.4(\mathrm{C}=\mathrm{O})\end{array}$ \\
\hline \multirow[t]{2}{*}{$3 e$} & $\begin{array}{l}248 / 250 \\
{[\mathrm{M}+\mathrm{H}]^{+}}\end{array}$ & $\begin{array}{l}1.42(3 \mathrm{H}, \mathrm{d}, J=6.6 \mathrm{~Hz}, \mathrm{OCHMe}), 4.30\left(2 \mathrm{H}, \text { br s. } \mathrm{NH}_{2}\right), 4.78(1 \mathrm{H}, \mathrm{q}, \\
J=6.6 \mathrm{~Hz}, \mathrm{OCHMe}), 6.94(1 \mathrm{H}, \mathrm{dd}, J=2.7 \mathrm{~Hz}, J=9.8 \mathrm{~Hz}, \mathrm{Ar}-\mathrm{H}-6) \\
7.19(1 \mathrm{H}, \mathrm{d}, J=2.7 \mathrm{~Hz}, \mathrm{Ar}-\mathrm{H}-2), 7.51(1 \mathrm{H}, \mathrm{d}, J=9.0 \mathrm{~Hz}, \mathrm{Ar}-\mathrm{H}-5), 9.38 \\
(1 \mathrm{H}, \mathrm{br} \text { s., NH})\end{array}$ \\
\hline & & $\begin{array}{l}\text { 19.0 (OCHMe), } 73.6(\mathrm{OCHMe}), 116.5\left(\mathrm{C}_{6}-\mathrm{Ar}\right), 117.7\left(\mathrm{C}_{2}-\mathrm{Ar}\right), 123.4 \\
\left(\mathrm{Cl}-\mathrm{C}_{4}-\mathrm{Ar}\right), 131.4\left(\mathrm{Cl}-\mathrm{C}_{5}-\mathrm{Ar}\right), 131.9\left(\mathrm{Cl}^{-} \mathrm{C}_{3}-\mathrm{Ar}\right), 157.1\left(\mathrm{Ar}-\mathrm{C}_{1}-\mathrm{O}\right), 169.8 \\
(\mathrm{C}=\mathrm{O})\end{array}$ \\
\hline \multirow[t]{2}{*}{$3 f$} & $\begin{array}{l}263 / 265 \\
{[\mathrm{M}+\mathrm{H}]^{+}}\end{array}$ & $\begin{array}{l}0.91\left(3 \mathrm{H}, \mathrm{t}, J=7.5 \mathrm{~Hz}, \mathrm{CH}_{2} \mathrm{CH}_{3}\right), 1.81\left(2 \mathrm{H}, \mathrm{m}, \mathrm{CH}_{2} \mathrm{CH}_{3}\right), 4.31(2 \mathrm{H}, \text { br s., } \\
\left.\mathrm{NH}_{2}\right), 4.59\left(1 \mathrm{H}, \mathrm{t}, J=6.0 \mathrm{~Hz}, \mathrm{OCHCH} \mathrm{CH}_{3}\right), 6.94(1 \mathrm{H}, \mathrm{dd}, J=3.0 \mathrm{~Hz}, \\
J=9.0 \mathrm{~Hz}, \mathrm{Ar}-\mathrm{H}-6), 7.19(1 \mathrm{H}, \mathrm{d}, J=3.0 \mathrm{~Hz}, \mathrm{Ar}-\mathrm{H}-2), 7.51(1 \mathrm{H}, \mathrm{d}, J=9.0 \\
\mathrm{Hz}, \mathrm{Ar}-\mathrm{H}-5), 9.38(1 \mathrm{H}, \mathrm{br} \mathrm{s} ., \mathrm{NH})\end{array}$ \\
\hline & & $\begin{array}{l}9.7\left(\mathrm{CH}_{2} \mathrm{CH}_{3}\right), 26.0\left(\mathrm{CH}_{2} \mathrm{CH}_{3}\right), 78.7\left(\mathrm{OCHCH}_{2} \mathrm{CH}_{3}\right), 116.6\left(\mathrm{C}_{6}-\mathrm{Ar}\right), 117.8 \\
\left(\mathrm{C}_{2}-\mathrm{Ar}\right), 123.4\left(\mathrm{Cl}-\mathrm{C}_{4}-\mathrm{Ar}\right), 131.4\left(\mathrm{C}_{3}-\mathrm{Ar}\right), 131.9\left(\mathrm{Cl}-\mathrm{C}_{5}-\mathrm{Ar}\right), 157.5 \\
\left(\mathrm{Ar}-\mathrm{C}_{1}-\mathrm{O}\right), 169.1(\mathrm{C}=\mathrm{O})\end{array}$ \\
\hline \multirow[t]{2}{*}{$3 g$} & $\begin{array}{l}194 / 196 \\
{[\mathrm{M}+\mathrm{H}]^{+}}\end{array}$ & $\begin{array}{l}1.57(3 \mathrm{H}, \mathrm{d}, J=6.9 \mathrm{~Hz}, \mathrm{OCHMe}), 2.30(3 \mathrm{H}, \mathrm{s}, 4-\mathrm{Me}-\mathrm{Ar}), 3.87(2 \mathrm{H}, \\
\left.\text { br s., } \mathrm{NH}_{2}\right), 4.73(1 \mathrm{H}, \mathrm{d}, J=6.9 \mathrm{~Hz}, \mathrm{OCHMe}), 6.77-6.81(2 \mathrm{H}, \mathrm{m}, \mathrm{ArH}), \\
7.09(2 \mathrm{H}, \mathrm{d}, J=8.1 \mathrm{~Hz}, \mathrm{ArH}), 7.77(1 \mathrm{H}, \mathrm{br} \mathrm{s} ., \mathrm{NH})\end{array}$ \\
\hline & & $\begin{array}{l}18.7(\mathrm{OCHMe}), 20.6\left(\mathrm{Me}^{1} \mathrm{C}_{4}-\mathrm{Ar}\right), 74.7(\mathrm{OCHMe}), 115.3\left(\mathrm{Me}-\mathrm{C}_{2,6}-\mathrm{Ar}\right), \\
130.2\left(\mathrm{Me}-\mathrm{C}_{3,5}-\mathrm{Ar}\right), 131.6\left(\mathrm{Me}-\mathrm{C}_{4}-\mathrm{Ar}\right), 154.6\left(\mathrm{Ar}-\mathrm{C}_{1}-\mathrm{O}\right), 172.6(\mathrm{C}=\mathrm{O})\end{array}$ \\
\hline
\end{tabular}




\begin{tabular}{|c|c|c|}
\hline Compd. & Mass $(m / z)$ & ${ }^{1} \mathrm{H} \operatorname{NMR}(\delta, \mathrm{ppm})$ and ${ }^{13} \mathrm{C} \operatorname{NMR}(\delta, \mathrm{ppm})$ \\
\hline \multirow[t]{2}{*}{$3 h$} & $\begin{array}{l}208 / 210 \\
{[\mathrm{M}+\mathrm{H}]^{+}}\end{array}$ & $\begin{array}{l}\left.1.02\left(3 \mathrm{H}, \mathrm{t}, J=7.5 \mathrm{~Hz}, \mathrm{CH}_{2} \mathrm{CH}_{3}\right), 1.87-2.03\left(2 \mathrm{H}, \mathrm{m}, \mathrm{CH}_{2} \mathrm{CH}_{3}\right)\right), 2.29 \\
(3 \mathrm{H}, \mathrm{s}, p-M e-\mathrm{Ar}), 3.85\left(2 \mathrm{H}, \mathrm{br} \mathrm{s} ., \mathrm{NH}_{2}\right), 4.58(1 \mathrm{H}, \mathrm{dd}, J=6.6 \mathrm{~Hz}, 7.5 \\
\left.\mathrm{Hz}, \mathrm{OCHCH} \mathrm{CH}_{3}\right), 6.77-6.82(2 \mathrm{H}, \mathrm{m}, \mathrm{ArH}), 7.09(2 \mathrm{H}, \mathrm{d}, J=8.1 \mathrm{~Hz}, \\
\text { ArH), } 7.73(1 \mathrm{H}, \text { br s., NH})\end{array}$ \\
\hline & & $\begin{array}{l}9.3\left(\mathrm{CH}_{2} \mathrm{CH}_{3}\right), 20.5\left(\mathrm{Me}-\mathrm{C}_{4}-\mathrm{Ar}\right), 26.1\left(\mathrm{CH}_{2} \mathrm{CH}_{3}\right), 79.6\left(\mathrm{OCHCH}_{2} \mathrm{CH}_{3}\right), \\
115.3\left(\mathrm{Me}-\mathrm{C}_{2,6}-\mathrm{Ar}\right), 130.2\left(\mathrm{Me}-\mathrm{C}_{3,5}-\mathrm{Ar}\right), 131.5\left(\mathrm{Me}-\mathrm{C}_{4}-\mathrm{Ar}\right), 155.2 \\
\left(\mathrm{Ar}-\mathrm{C}_{1}-\mathrm{O}\right), 172.0(\mathrm{C}=\mathrm{O})\end{array}$ \\
\hline \multirow[t]{2}{*}{$5 a$} & $\begin{array}{l}299 / 301 \\
{[\mathrm{M}]^{+}}\end{array}$ & $\begin{array}{l}1.78(3 \mathrm{H}, \mathrm{d}, J=6.6 \mathrm{~Hz}, \mathrm{OCHMe}), 5.32(1 \mathrm{H}, \mathrm{q}, J=6.6 \mathrm{~Hz}, \mathrm{OCHMe}) \\
6.84-6.89(2 \mathrm{H}, \mathrm{m}, \mathrm{ArH}), 7.36-7.39(2 \mathrm{H}, \mathrm{m}, \mathrm{ArH}), 11.08(1 \mathrm{H}, \mathrm{s}, \mathrm{NH})\end{array}$ \\
\hline & & 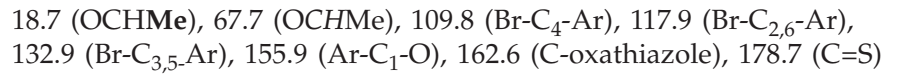 \\
\hline \multirow[t]{2}{*}{$5 b$} & $\begin{array}{l}314 / 316 \\
{[\mathrm{M}]^{+}}\end{array}$ & $\begin{array}{l}0.95\left(3 \mathrm{H}, \mathrm{t}, J=7.5 \mathrm{~Hz}, \mathrm{CH}_{2} \mathrm{CH}_{3}\right), 2.03-2.24\left(2 \mathrm{H}, \mathrm{m}, \mathrm{CH}_{2} \mathrm{CH}_{3}\right) \\
5.08\left(1 \mathrm{H}, \mathrm{t}, J=6.6 \mathrm{~Hz}, \mathrm{OCHCH}_{2} \mathrm{CH}_{3}\right), 6.84-6.89(2 \mathrm{H}, \mathrm{m}, \mathrm{ArH}) \\
7.38-7.43(2 \mathrm{H}, \mathrm{m}, \mathrm{ArH}), 10.83(1 \mathrm{H}, \mathrm{br} \mathrm{s.}, \mathrm{NH})\end{array}$ \\
\hline & & $\begin{array}{l}9.4\left(\mathrm{CH}_{2} \mathrm{CH}_{3}\right), 26.3\left(\mathrm{CH}_{2} \mathrm{CH}_{3}\right), 72.7\left(\mathrm{OCHCH}_{2} \mathrm{CH}_{3}\right), 115.0\left(\mathrm{Br}_{-} \mathrm{C}_{4}-\mathrm{Ar}\right) \\
\text { 117.7 }\left(\mathrm{Br}-\mathrm{C}_{2,6}-\mathrm{Ar}\right), 132.7\left(\mathrm{Br}-\mathrm{C}_{3,5}-\mathrm{Ar}\right), 155.9\left(\mathrm{Ar}_{1}-\mathrm{C}{ }_{1}-\mathrm{O}\right), 162.0 \text { (C-oxathia- } \\
\text { zole), } 178.5(\mathrm{C}=\mathrm{S})\end{array}$ \\
\hline \multirow[t]{2}{*}{$5 c$} & $\begin{array}{l}256 / 268 \\
{[\mathrm{M}]^{+}}\end{array}$ & $\begin{array}{l}1.27(1 \mathrm{H}, \mathrm{s}, \mathrm{SH}), 1.77(3 \mathrm{H}, \mathrm{d}, J=6.6 \mathrm{~Hz}, \mathrm{OCHMe}), 5.32(1 \mathrm{H}, \mathrm{d} \\
J=6.6 \mathrm{~Hz}, \mathrm{OCHMe}), 6.89-6.96(2 \mathrm{H}, \mathrm{m}, \mathrm{ArH}), 7.24-7.29(2 \mathrm{H}, \mathrm{m}, \mathrm{ArH})\end{array}$ \\
\hline & & $\begin{array}{l}\text { 18.6 (OCHMe), } 67.7 \text { (OCHMe), } 117.4\left(\mathrm{Cl}_{-} \mathrm{C}_{4}-\mathrm{Ar}\right), 129.7\left(\mathrm{Cl}^{-} \mathrm{C}_{2,6}-\mathrm{Ar}\right), \\
130.1\left(\mathrm{Cl}-\mathrm{C}_{3,5}-\mathrm{Ar}\right), 155.1\left(\mathrm{Ar}-\mathrm{C}_{1}-\mathrm{O}\right), 162.5 \text { (C-oxathiazole), } 178.6(\mathrm{C}=\mathrm{S})\end{array}$ \\
\hline \multirow[t]{2}{*}{$5 d$} & $\begin{array}{l}270 / 272 \\
{[\mathrm{M}]^{+}}\end{array}$ & $\begin{array}{l}1.09\left(3 \mathrm{H}, \mathrm{t}, J=7.5 \mathrm{~Hz}, \mathrm{CH}_{2} \mathrm{CH}_{3}\right), 2.23-2.63\left(2 \mathrm{H}, \mathrm{m}, \mathrm{CH}_{2} \mathrm{CH}_{3}\right) \\
5.08\left(1 \mathrm{H}, \mathrm{t}, J=6.6 \mathrm{~Hz}, \mathrm{OCHCH}_{2} \mathrm{CH}_{3}\right) .6 .88-6.94(2 \mathrm{H}, \mathrm{m}, \mathrm{ArH}) \\
7.23-7.28(2 \mathrm{H}, \mathrm{m}, \mathrm{ArH}), 10.65(1 \mathrm{H}, \mathrm{s}, \mathrm{NH})\end{array}$ \\
\hline & & $\begin{array}{l}\text { 9.4 }\left(\mathrm{CH}_{2} \mathrm{CH}_{3}\right), 18.6\left(\mathrm{CH}_{2} \mathrm{CH}_{3}\right), 72.8\left(\mathrm{OCHCH}_{2} \mathrm{CH}_{3}\right), 117.3\left(\mathrm{Cl}_{-} \mathrm{C}_{4}-\mathrm{Ar}\right), \\
127.7\left(\mathrm{Cl}^{-} \mathrm{C}_{2,6}-\mathrm{Ar}\right), 129.2\left(\mathrm{Cl}_{3,5}-\mathrm{Ar}\right), 155.5\left(\mathrm{Ar}-\mathrm{C}_{1}-\mathrm{O}\right), 162.1 \text { (C-oxathia- } \\
\text { zole), } 178.6(\mathrm{C}=\mathrm{S})\end{array}$ \\
\hline \multirow[t]{2}{*}{$5 e$} & $\begin{array}{l}290 / 292 \\
{[\mathrm{M}]^{+}}\end{array}$ & $\begin{array}{l}1.27(1 \mathrm{H}, \mathrm{s}, \mathrm{SH}), 1.83(3 \mathrm{H}, \mathrm{d}, J=6.3 \mathrm{~Hz}, \mathrm{OCHMe}), 5.39(1 \mathrm{H}, \mathrm{q}, J=6.3 \\
\mathrm{Hz},(\mathrm{OCHMe}), 6.93(1 \mathrm{H}, \mathrm{dd}, J=3.0 \mathrm{~Hz}, 8.1 \mathrm{~Hz}, \mathrm{Ar}-\mathrm{H}-6), 7.10(1 \mathrm{H}, \mathrm{d} \\
J=3.0 \mathrm{~Hz}, \mathrm{Ar}-\mathrm{H}-2), 7.43(1 \mathrm{H}, \mathrm{d}, J=8.1 \mathrm{~Hz}, \mathrm{Ar}-\mathrm{H}-5)\end{array}$ \\
\hline & & $\begin{array}{l}18.7 \text { (OCHMe), } 67.9(\mathrm{OCHMe}), 115.7\left(\mathrm{C}_{6}-\mathrm{Ar}\right), 118.3\left(\mathrm{C}_{2}-\mathrm{Ar}\right), 126.4 \\
\left(\mathrm{Cl}-\mathrm{C}_{4}-\mathrm{Ar}\right), 131.0\left(\mathrm{Cl}-\mathrm{C}_{5}-\mathrm{Ar}\right), 133.0\left(\mathrm{Cl}-\mathrm{C}_{3}-\mathrm{Ar}\right), 155.7\left(\mathrm{Ar}-\mathrm{C}_{1}-\mathrm{O}\right), 162.2 \\
\text { (C-oxathiazole), } 178.7(\mathrm{C}=\mathrm{S})\end{array}$ \\
\hline \multirow[t]{2}{*}{$5 f$} & $\begin{array}{l}304 / 306 \\
{[\mathrm{M}]^{+}}\end{array}$ & $\begin{array}{l}1.09\left(3 \mathrm{H}, \mathrm{t}, J=7.5 \mathrm{~Hz}, \mathrm{CH}_{2} \mathrm{CH}_{3}\right), 1.27(1 \mathrm{H}, \mathrm{s}, \mathrm{SH}), 2.06-2.24 \\
\left(2 \mathrm{H}, \mathrm{m}, \mathrm{CH}_{2} \mathrm{CH}_{3}\right), 5.08\left(1 \mathrm{H}, \mathrm{t}, J=6.9 \mathrm{~Hz}, \mathrm{OCHCH} \mathrm{CH}_{3}\right), 6.84 \\
(1 \mathrm{H}, \mathrm{dd}, J=3.0 \mathrm{~Hz}, 9.0 \mathrm{~Hz}, \mathrm{ArH}), 7.10(1 \mathrm{H}, \mathrm{q}, J=2.7 \mathrm{~Hz}, \mathrm{ArH}), \\
7.35(1 \mathrm{H}, \mathrm{d}, J=9.0 \mathrm{~Hz}, \mathrm{ArH})\end{array}$ \\
\hline & & $\begin{array}{l}9.3\left(\mathrm{CH}_{2} \mathrm{CH}_{3}\right), 26.2\left(\mathrm{CH}_{2} \mathrm{CH}_{3}\right), 72.9\left(\mathrm{OCHCH}_{2} \mathrm{CH}_{3}\right), 115.4\left(\mathrm{C}_{6}-\mathrm{Ar}\right), \\
\left.118.1\left(\mathrm{C}_{2}-\mathrm{Ar}\right), 126.1\left(\mathrm{Cl}^{-} \mathrm{C}_{4}-\mathrm{Ar}\right), 131.0\left(\mathrm{Cl}-\mathrm{C}_{5}-\mathrm{Ar}\right), 133.3 \mathrm{Cl}-\mathrm{C}_{3}-\mathrm{Ar}\right), 155.9 \\
\left(\mathrm{Ar}-\mathrm{C}_{1}-\mathrm{O}\right), 161.6(\mathrm{C} \text {-oxathiazole }), 178.5(\mathrm{C}=\mathrm{S})\end{array}$ \\
\hline
\end{tabular}


T. Akhtar et al: In vitro antitumor and antiviral activities of new benzothiazole and 1,3,4-oxadiazole-2-thione derivatives, Acta Pharm. 58 (2008) 135-149.

Table II. Continuation

\begin{tabular}{|c|c|c|}
\hline Compd. & Mass $(m / z)$ & ${ }^{1} \mathrm{H}$ NMR $(\delta, \mathrm{ppm})$ and ${ }^{13} \mathrm{C} \mathrm{NMR}(\delta, \mathrm{ppm})$ \\
\hline \multirow[t]{2}{*}{$5 \mathrm{~g}$} & $\begin{array}{l}236 \\
{[\mathrm{M}]^{+}}\end{array}$ & $\begin{array}{l}1.76(3 \mathrm{H}, \mathrm{d}, J=6.6 \mathrm{~Hz}, \mathrm{OCHMe}), 2.30(3 \mathrm{H}, \mathrm{s}, p-\mathrm{Me}-\mathrm{Ar}), 5.33(1 \mathrm{H}, \mathrm{d}, \\
J=6.6 \mathrm{~Hz}, \mathrm{OCHMe}), 6.87(2 \mathrm{H}, \mathrm{d}, J=8.7 \mathrm{~Hz}, \operatorname{ArH}), 7.10(2 \mathrm{H}, \mathrm{d} \\
J=8.4 \mathrm{~Hz}, \mathrm{ArH}), 9.91(1 \mathrm{H}, \mathrm{s}, \mathrm{NH})\end{array}$ \\
\hline & & $\begin{array}{l}18.7(\mathrm{OCHMe}), 20.6(p-\mathrm{Me}-\mathrm{Ar}), 67.6(\mathrm{OCHMe}), 116.1\left(\mathrm{Me}-\mathrm{C}_{2,6}-\mathrm{Ar}\right) \text {, } \\
\left.\text { 130.2 (Me- } \mathrm{C}_{3,5}-\mathrm{Ar}\right), 132.2\left(\mathrm{Me}-\mathrm{C}_{4}-\mathrm{Ar}\right), 154.5\left(\mathrm{Ar}-\mathrm{C}_{1}-\mathrm{O}\right), 163.2(\mathrm{C} \text {-oxat- } \\
\text { hiazole), } 178.6(\mathrm{C}=\mathrm{S})\end{array}$ \\
\hline \multirow[t]{2}{*}{$5 \mathrm{~h}$} & $\begin{array}{l}250 \\
{[\mathrm{M}]^{+}}\end{array}$ & $\begin{array}{l}1.09\left(3 \mathrm{H}, \mathrm{t}, J=7.5 \mathrm{~Hz}, \mathrm{CH}_{2} \mathbf{C H}_{3}\right), 2.03-2.22\left(2 \mathrm{H}, \mathrm{m}, \mathrm{CH}_{2} \mathrm{CH}_{3}\right) \\
2.32(3 \mathrm{H}, \mathrm{s}, p-\mathrm{Me}-\mathrm{Ar}), 7.03-7.22(4 \mathrm{H}, \mathrm{m}, \mathrm{ArH}), 11.62(1 \mathrm{H}, \mathrm{s}, \mathrm{NH})\end{array}$ \\
\hline & & $\begin{array}{l}\text { 9.6 }\left(\mathrm{CH}_{2} \mathrm{CH}_{3}\right), 20.7\left(\mathrm{CH}_{2} \mathrm{CH}_{3}\right), 26.6(4-\mathrm{Me}-\mathrm{Ar}), 73.0\left(\mathrm{OCHCH}_{2} \mathrm{CH}_{3}\right) \\
116.1\left(\left(\mathrm{Me}-\mathrm{C}_{2,6}-\mathrm{Ar}\right), 130.3\left(\mathrm{Me}-\mathrm{C}_{3,5}-\mathrm{Ar}\right), 132.4\left(\mathrm{Me}-\mathrm{C}_{4}-\mathrm{Ar}\right), 155.1\right. \\
\left(\mathrm{Ar}-\mathrm{C}_{1}-\mathrm{O}\right), 163.2(\mathrm{C}-\mathrm{oxathiazole}), 178.9(\mathrm{C}=\mathrm{S})\end{array}$ \\
\hline \multirow[t]{2}{*}{$6 a$} & $\begin{array}{l}491 / 403 \\
{[\mathrm{M}+\mathrm{H}]^{+}}\end{array}$ & $\begin{array}{l}1.65(3 \mathrm{H}, \mathrm{d}, J=6.6 \mathrm{~Hz}, \mathrm{OCHMe}), 4.43\left(2 \mathrm{H}, \mathrm{s}, \mathrm{SCH}_{2}\right), 5.84(1 \mathrm{H}, \mathrm{d} \\
J=6.6 \mathrm{~Hz}, \mathrm{OCHMe}), 6.95-7.01(2 \mathrm{H}, \mathrm{m}, \mathrm{ArH}), 7.32(1 \mathrm{H}, \mathrm{dt}, J=0.9 \mathrm{~Hz} \\
7.9 \mathrm{~Hz}, \mathrm{ArH}), 7.39-7.48(3 \mathrm{H}, \mathrm{m}, \mathrm{ArH}), 7.77(1 \mathrm{H}, \mathrm{d}, J=7.8 \mathrm{~Hz}, \mathrm{ArH}) \\
7.99(1 \mathrm{H}, \mathrm{d}, J=7.8 \mathrm{~Hz}, \mathrm{ArH}), 12.78(1 \mathrm{H}, \mathrm{s}, \mathrm{NH})\end{array}$ \\
\hline & & $\begin{array}{l}18.9(\mathrm{OCHMe}), 36.1\left(\mathrm{SCH}_{2}\right), 67.4(\mathrm{OCHMe}), 113.9\left(\mathrm{Br}^{-} \mathrm{C}_{4}-\mathrm{Ar}\right), 118.5 \\
\left(\mathrm{Br}-\mathrm{C}_{2,6}-\mathrm{Ar}\right), 121.2,122.4,124.2,126.7 \text { [Ar-C (benzothiazole)], } 132.9 \\
\left(\mathrm{Br}-\mathrm{C}_{3,5}-\mathrm{Ar}\right), 148.9(\mathrm{Ar}-\mathrm{C}-\mathrm{N}), 156.3\left(\mathrm{Ar}-\mathrm{C}_{1}-\mathrm{O}\right) ; 158.1,164.4 \text { (C-oxathia- } \\
\text { zole), } 166.7(\mathrm{C}=\mathrm{O}), 166.8(\mathrm{~S}-\mathrm{C}-\mathrm{N})\end{array}$ \\
\hline \multirow[t]{2}{*}{$6 b$} & $\begin{array}{l}504 / 506 \\
{[\mathrm{M}]^{+}}\end{array}$ & $\begin{array}{l}0.92\left(3 \mathrm{H}, \mathrm{t}, J=7.4 \mathrm{~Hz}, \mathrm{CH}_{2} \mathrm{CH}_{3}\right), 1.92-2.07\left(2 \mathrm{H}, \mathrm{m}, \mathrm{CH}_{2} \mathrm{CH}_{3}\right), 4.42 \\
\left(2 \mathrm{H}, \mathrm{s}, \mathrm{SCH}_{2}\right), 5.64\left(1 \mathrm{H}, \mathrm{q}, J=6.6 \mathrm{~Hz}, \mathrm{OCHCH} \mathrm{CH}_{3}\right), 6.95-7.00(2 \mathrm{H}, \\
\mathrm{m}, \mathrm{ArH}), 7.32(1 \mathrm{H}, \mathrm{dt}, J=0.6 \mathrm{~Hz}, 7.35 \mathrm{~Hz}, \mathrm{ArH}), 7.39-7.47(3 \mathrm{H}, \mathrm{m}, \\
\mathrm{ArH}), 7.77(1 \mathrm{H}, \mathrm{d}, J=8.1 \mathrm{~Hz}, \mathrm{ArH}), 7.99(1 \mathrm{H}, \mathrm{d}, J=7.8 \mathrm{~Hz}, \mathrm{ArH}) \\
12.78(1 \mathrm{H}, \mathrm{s}, \mathrm{NH})\end{array}$ \\
\hline & & $\begin{array}{l}9.5\left(\mathrm{CH}_{2} \mathrm{CH}_{3}\right), 26.4\left(\mathrm{CH}_{2} \mathrm{CH}_{3}\right), 36.1\left(\mathrm{SCH}_{2}\right), 72.2\left(\mathrm{OCHCH}_{2} \mathrm{CH}_{3}\right), 113.9 \\
(\mathrm{Br}-\mathrm{C}-\mathrm{Ar}), 118.5,\left({\mathrm{Br}-\mathrm{C}_{2,6}}^{-} \mathrm{Ar}\right), 121.2,122.3,124.2,126.7 \text { [Ar-C (benzot- } \\
\left.\text { hiazole)], 132.8 (Br- } \mathrm{C}_{3,5}-\mathrm{Ar}\right), 149.0(\mathrm{Ar}-\mathrm{C}-\mathrm{N}), 156.7\left(\mathrm{Ar}-\mathrm{C}_{1}-\mathrm{O}\right) ; 158.0, \\
\text { 164.4 (C-oxathiazole), } 166.2(\mathrm{C}=\mathrm{O}), 166.7(\mathrm{~S}-\mathrm{C}-\mathrm{N})\end{array}$ \\
\hline \multirow[t]{2}{*}{$6 c$} & $\begin{array}{l}446 / 448 \\
{[\mathrm{M}+\mathrm{H}]^{+}}\end{array}$ & $\begin{array}{l}1.65(3 \mathrm{H}, \mathrm{d}, J=6.6 \mathrm{~Hz}, \mathrm{OCHMe}), 4.43\left(2 \mathrm{H}, \mathrm{s}, \mathrm{SCH}_{2}\right), 5.84(1 \mathrm{H}, \mathrm{q}, \\
J=6.6 \mathrm{~Hz}, \mathrm{OCHCH}), 7.00-7.06(2 \mathrm{H}, \mathrm{m}, \mathrm{ArH}), 7.27-7.35(3 \mathrm{H}, \mathrm{m}, \\
\mathrm{ArH}), 7.45(1 \mathrm{H}, \mathrm{dt}, J=0.6 \mathrm{~Hz}, 7.9 \mathrm{~Hz}, \mathrm{ArH}), 7.77(1 \mathrm{H}, \mathrm{d}, J=8.1 \mathrm{~Hz}, \\
\text { ArH), } 7.99(1 \mathrm{H}, \mathrm{d}, J=7.8 \mathrm{~Hz}, \mathrm{ArH}), 12.78(1 \mathrm{H}, \mathrm{s}, \mathrm{NH})\end{array}$ \\
\hline & & $\begin{array}{l}18.9\left(\mathrm{OCHCH}_{3}\right), 36.1\left(\mathrm{SCH}_{2}\right), 67.5\left(\mathrm{OCHCH}_{3}\right), 118.1\left(\mathrm{Cl}-\mathrm{C}_{2,6}-\mathrm{Ar}\right), 121.2, \\
\left.122.3,124.3,126.1,126.7 \text { [Ar-C (benzothiazole }), \mathrm{Cl}^{-} \mathrm{C}_{4}-\mathrm{Ar}\right], 129.9 \\
\left(\mathrm{Cl}-\mathrm{C}_{3,5}-\mathrm{Ar}\right), 149.0(\mathrm{Ar}-\mathrm{C}-\mathrm{N}), 155.8\left(\text { Ar- } \mathrm{C}_{1}-\mathrm{O}\right), 158.1,164.4 \text { (C-oxathia- } \\
\text { zole }), 166.7(\mathrm{C}=\mathrm{O}), 166.8(\mathrm{~S}-\mathrm{C}-\mathrm{N})\end{array}$ \\
\hline \multirow[t]{2}{*}{$6 d$} & $\begin{array}{l}461 / 463 \\
{[\mathrm{M}+\mathrm{H}]^{+}}\end{array}$ & $\begin{array}{l}8.92\left(3 \mathrm{H}, \mathrm{t}, J=7.30 \mathrm{~Hz}, \mathrm{CH}_{2} \mathrm{CH}_{3}\right), 1.97-2.07\left(2 \mathrm{H}, \mathrm{m}, \mathrm{CH}_{2} \mathrm{CH}_{3}\right), 4.43 \\
\left(2 \mathrm{H}, \mathrm{s}, \mathrm{SCH}_{2}\right), 5.64\left(1 \mathrm{H}, \mathrm{t}, J=6.75 \mathrm{~Hz}, \mathrm{OCHCH} \mathrm{CH}_{3}\right), 7.00-7.05(2 \mathrm{H}, \\
\mathrm{m}, \mathrm{ArH}), 7.26-7.35(3 \mathrm{H}, \mathrm{m}, \mathrm{ArH}), 7.24(1 \mathrm{H}, \mathrm{dt}, J=1.2 \mathrm{~Hz}, 8.2 \mathrm{~Hz}, \\
\mathrm{ArH}), 7.77(1 \mathrm{H}, \mathrm{d}, J=7.8 \mathrm{~Hz}, \mathrm{ArH}), 7.99(1 \mathrm{H}, \mathrm{d}, J=7.8 \mathrm{~Hz}, \mathrm{ArH}) \\
12.78(1 \mathrm{H}, \mathrm{s}, \mathrm{NH})\end{array}$ \\
\hline & & 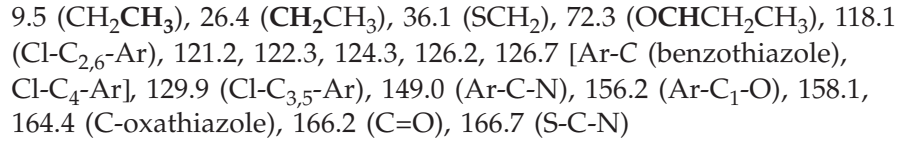 \\
\hline
\end{tabular}




\begin{tabular}{|c|c|c|}
\hline Compd. & $\operatorname{Mass}(m / z)$ & ${ }^{1} \mathrm{H} \operatorname{NMR}(\delta, \mathrm{ppm})$ and ${ }^{13} \mathrm{C} \operatorname{NMR}(\delta, \mathrm{ppm})$ \\
\hline \multirow[t]{2}{*}{$6 e$} & $\begin{array}{l}481 / 483 \\
{[\mathrm{M}+\mathrm{H}]^{+}}\end{array}$ & $\begin{array}{l}1.65(3 \mathrm{H}, \mathrm{d}, J=6.3 \mathrm{~Hz}, \mathrm{OCHMe}), 4.43\left(2 \mathrm{H}, \mathrm{s}, \mathrm{SCH}_{2}\right), 5.93(1 \mathrm{H}, \mathrm{q}, J= \\
6.3 \mathrm{~Hz}, \mathrm{OCHMe}), 7.03(1 \mathrm{H}, \mathrm{dd}, J=3.0 \mathrm{~Hz}, 8.7 \mathrm{~Hz}, \mathrm{ArH}), 7.29-7.51 \\
(4 \mathrm{H}, \mathrm{m}, \mathrm{ArH}), 7.77(1 \mathrm{H}, \mathrm{d}, J=8.1 \mathrm{~Hz}, \mathrm{ArH}), 7.98(1 \mathrm{H}, \mathrm{d}, J=7.5 \mathrm{~Hz} \\
\text { ArH), } 12.78(1 \mathrm{H}, \mathrm{s}, \mathrm{NH})\end{array}$ \\
\hline & & 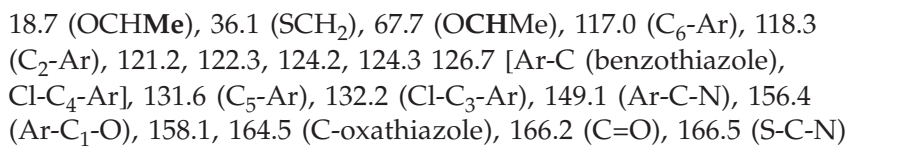 \\
\hline \multirow[t]{2}{*}{$6 f$} & $\begin{array}{l}495 / 497 \\
{[\mathrm{M}+\mathrm{H}]^{+}}\end{array}$ & $\begin{array}{l}1.03\left(3 \mathrm{H}, \mathrm{t}, J=7.4 \mathrm{~Hz}, \mathrm{CH}_{2} \mathrm{CH}_{3}\right), 2.10-2.20\left(2 \mathrm{H}, \mathrm{m}, \mathrm{CH}_{2} \mathrm{CH}_{3}\right), 4.63 \\
\left(2 \mathrm{H}, \mathrm{s}, \mathrm{SCH}_{2}\right), 5.82\left(1 \mathrm{H}, \mathrm{t}, J=6.8 \mathrm{~Hz}, \mathrm{OCHCH} \mathrm{CH}_{3}\right), 7.15(1 \mathrm{H}, \mathrm{dd}, J= \\
3.0 \mathrm{~Hz}, 9.0 \mathrm{~Hz}, \mathrm{ArH}), 7.36(1 \mathrm{H}, \mathrm{dt}, J=1.2 \mathrm{~Hz}, 8.0 \mathrm{~Hz}, \mathrm{ArH}), 7.44(1 \mathrm{H}, \\
\mathrm{d}, J=3.0 \mathrm{~Hz}, \mathrm{ArH}), 7.49(\mathrm{dt}, J=1.2 \mathrm{~Hz}, 7.35 \mathrm{~Hz}, \mathrm{ArH}), 7.55(1 \mathrm{H}, \mathrm{dd}, \\
J=9.0 \mathrm{~Hz}, \mathrm{ArH}), 7.79(1 \mathrm{H}, \mathrm{d}, J=7.50 \mathrm{~Hz}, \mathrm{ArH}), 7.95(1 \mathrm{H}, \mathrm{d}, J=7.5 \\
\mathrm{Hz}, \mathrm{Ar}), 12.78(1 \mathrm{H}, \mathrm{s}, \mathrm{NH})\end{array}$ \\
\hline & & $\begin{array}{l}18.7\left(\mathrm{CH}_{2} \mathrm{CH}_{3}\right), 28.7\left(\mathrm{CH}_{2} \mathrm{CH}_{3}\right), 35.9\left(\mathrm{SCH}_{2}\right), 72.7\left(\mathrm{OCHCH}_{2} \mathrm{Me}\right), 116.7 \\
\left(\mathrm{C}_{6}-\mathrm{Ar}\right), 118.2\left(\mathrm{C}_{2}-\mathrm{Ar}\right), 121.7,123.9,124.42,126.3 \text { [Ar-C (benzothiazo- } \\
\left.\text { le), } \mathrm{Cl}-\mathrm{C}_{4}-\mathrm{Ar}\right], 131.3\left(\mathrm{C}_{5}-\mathrm{Ar}\right), 132.2\left(\mathrm{Cl}-\mathrm{C}_{3}-\mathrm{Ar}\right), 149.0(\mathrm{Ar}-\mathrm{C}-\mathrm{N}), 157.0 \\
\left(\mathrm{Ar}-\mathrm{C}_{1}-\mathrm{O}\right), 161.7,164.5(\mathrm{C} \text {-oxathiazole }), 166.5(\mathrm{C}=\mathrm{O}), 166.9(\mathrm{~S}-\mathrm{C}-\mathrm{N})\end{array}$ \\
\hline \multirow[t]{2}{*}{$6 \mathrm{~g}$} & $\begin{array}{l}426 \\
{[\mathrm{M}]^{+}}\end{array}$ & $\begin{array}{l}1.63(3 \mathrm{H}, \mathrm{d}, J=6.6 \mathrm{~Hz}, \mathrm{OCHMe}), 2.18(3 \mathrm{H}, \mathrm{s}, p-\mathrm{Me}-\mathrm{Ar}), 4.43(2 \mathrm{H}, \mathrm{s}, \\
\left.\mathrm{SCH}_{2}\right), 5.74(1 \mathrm{H}, \mathrm{d}, J=6.6 \mathrm{~Hz}, \mathrm{OCHMe}), 6.87(2 \mathrm{H}, \mathrm{d}, J=8.7 \mathrm{~Hz} \\
\mathrm{ArH}), 7.35(2 \mathrm{H}, \mathrm{d}, J=8.7 \mathrm{~Hz}, \mathrm{ArH}), 7.32(1 \mathrm{H}, \mathrm{dt}, J=0.9 \mathrm{~Hz}, 7.9 \mathrm{~Hz}, \\
\mathrm{ArH}), 7.45(1 \mathrm{H}, \mathrm{dt}, J=1.2 \mathrm{~Hz}, 8.2 \mathrm{~Hz}, \operatorname{ArH}), 7.77(1 \mathrm{H}, \mathrm{d}, J=8.1 \mathrm{~Hz}, \\
\text { ArH), } 7.99(1 \mathrm{H}, \mathrm{d}, J=7.8 \mathrm{~Hz}, \operatorname{ArH}), 12.77(1 \mathrm{H}, \mathrm{s}, \mathrm{NH})\end{array}$ \\
\hline & & $\begin{array}{l}19.1(\mathrm{OCHMe}), 20.2\left(\mathrm{Me}^{-} \mathrm{C}_{4}-\mathrm{Ar}\right), 36.1\left(\mathrm{SCH}_{2}\right), 67.3(\mathrm{OCHMe}), 116.3 \\
\left(\mathrm{Me}-\mathrm{C}_{2,6}-\mathrm{Ar}\right), 121.2,122.3,124.2,126.7[\mathrm{Ar}-\mathrm{C}(\text { benzothiazole })], 130.4 \\
\left(\mathrm{Me}-\mathrm{C}_{3,5}-\mathrm{Ar}\right), 131.3\left(\mathrm{Me}-\mathrm{C}_{4}-\mathrm{Ar}\right), 149.0(\mathrm{Ar}-\mathrm{C}-\mathrm{N}), 154.9\left(\mathrm{Ar}-\mathrm{C}_{1}-\mathrm{O}\right), 158.1, \\
164.2(\mathrm{C}-\text { oxathiazole }), 166.7(\mathrm{C}=\mathrm{O}), 167.3(\mathrm{~S}-\mathrm{C}-\mathrm{N})\end{array}$ \\
\hline \multirow[t]{2}{*}{$6 \mathrm{~h}$} & $\begin{array}{l}441 \\
{[\mathrm{M}+\mathrm{H}]^{+}}\end{array}$ & $\begin{array}{l}0.92\left(3 \mathrm{H}, \mathrm{t}, J=7.5 \mathrm{~Hz}, \mathrm{CH}_{2} \mathrm{CH}_{3}\right), 1.91-2.11\left(2 \mathrm{H}, \mathrm{m}, \mathrm{CH}_{2} \mathrm{CH}_{3}\right), 2.17 \\
(3 \mathrm{H}, \mathrm{s}, p-\mathrm{Me}-\mathrm{Ar}), 4.42(2 \mathrm{H}, \mathrm{s}, \mathrm{SCH}), 5.53(1 \mathrm{H}, \mathrm{t}, J=6.6 \mathrm{~Hz}, \\
\left.\mathrm{OCHCH}_{2} \mathrm{CH}_{3}\right), 6.87(2 \mathrm{H}, \mathrm{d}, J=8.4 \mathrm{~Hz}, \mathrm{ArH}), 7.03(2 \mathrm{H}, \mathrm{d}, J=8.4 \mathrm{~Hz}, \\
\mathrm{ArH}), 7.31(1 \mathrm{H}, \mathrm{t}, J=7.5 \mathrm{~Hz}, \mathrm{ArH}), 7.44(1 \mathrm{H}, \mathrm{t}, J=7.5 \mathrm{~Hz}, \mathrm{ArH}), 7.77 \\
(1 \mathrm{H}, \mathrm{d}, J=8.1 \mathrm{~Hz}, \mathrm{ArH}), 7.98(1 \mathrm{H}, \mathrm{d}, J=7.8 \mathrm{~Hz}, \mathrm{ArH}), 12.78(1 \mathrm{H}, \mathrm{s}, \\
\mathrm{NH})\end{array}$ \\
\hline & & $\begin{array}{l}\text { 9.6 }\left(\mathrm{CH}_{2} \mathrm{CH}_{3}\right), 20.5\left(\mathrm{Me}-\mathrm{C}_{4}-\mathrm{Ar}\right), 26.5\left(\mathrm{CH}_{2} \mathrm{CH}_{3}\right), 36.2\left(\mathrm{SCH}_{2}\right), 72.3 \\
\left(\mathrm{OCHCH}_{2} \mathrm{Me}\right), 116.2\left(\mathrm{Me}-\mathrm{C}_{2,6}-\mathrm{Ar}\right), 121.1,122.2,124.2,126.7 \text { [Ar-C } \\
\text { (benzothiazole)], } 130.4\left(\mathrm{Me}-\mathrm{C}_{3,5}-\mathrm{Ar}\right), 131.3\left(\mathrm{Me}-\mathrm{C}_{4}-\mathrm{Ar}\right), 149.6(\mathrm{Ar}-\mathrm{C}-\mathrm{N}), \\
155.3\left(\mathrm{Ar}-\mathrm{C}_{1}-\mathrm{O}\right), 158.3,164.3(\mathrm{C} \text {-oxathiazole }), 166.6(\mathrm{C}=\mathrm{O}), 166.8 \\
(\mathrm{~S}-\mathrm{C}-\mathrm{N})\end{array}$ \\
\hline
\end{tabular}

p-chlorophenol with 2-bromopropanoic acid, p-chlorophenol with 2-bromobutanoic acid, 3,4-dichlorophenol with 2-bromopropanoic acid, 3,4-dichlorophenol with 2-bromobutanoic acid, $p$-cresol with 2-bromopropanoic acid and $p$-cresol (d) with 2-bromobutanoic acid, respectively. 
General procedure for the synthesis of 4-alkyl-, 4-halo-, 3,4-dichlorophenoxyalkanoic methyl esters (2a-h). - 2-(4-Bromophenoxy)propanoic methyl ester (2a), 2-(4-bromophenoxy)butanoic methyl ester (2b), 2-(4-chlorophenoxy)propanoic methyl ester (2c), 2-(4-chlorophenoxy)butanoic methyl ester (2d), 2-(3,4-dichlorophenoxy)propanoic methyl ester (2e), 2-(3,4-dichlorophenoxy)butanoic methyl ester (2f), 2-( $p$-tolyloxy)propanoic methyl ester (2g), 2-( $p$-tolyloxy)butanoic methyl ester $(2 \mathrm{~h})$ were prepared according to the Fischer esterfication procedure (15), by treatment of $\mathbf{1 a}-\mathbf{h}$ with acidic $\mathrm{MeOH}$. Compounds 2a-h were used for the next step without further purification.

General procedure for the synthesis of 4-alkyl-, 4-halo-, 3,4-dichlorophenoxyalkanoic acid hydrazides $(3 \boldsymbol{a}-\boldsymbol{h})$. - To a solution of $2(3.80 \mathrm{mmol})$ in EtOH $(20 \mathrm{~mL})$, hydrazine hydrate $(5.0 \mathrm{~mL})$ was added and the solution was heated under reflux for 3-4 h. After cooling, the solution was evaporated to dryness and the residue was recrystallized from EtOH or $\mathrm{EtOH} / \mathrm{MeOH}$.

4-Bromophenoxypropionic acid hydrazide (3a), 4-bromophenoxybutyric acid hydrazide (3b), 4-chlorophenoxypropionic acid hydrazide (3c), 4-chlorophenoxybutyric acid hydrazide (3d), 3,4-dichlorophenoxypropionic acid hydrazide (3e), 3,4-dichlorophenoxybutyric acid hydrazide (3f), 4-methylphenoxypropionic acid hydrazide (3g) and 4-methylphenoxybutyric acid hydrazide (3h) were prepared from $2 \mathrm{a}(0.98 \mathrm{~g}), 2 \mathrm{~b}(1.04 \mathrm{~g}), \mathbf{2 c}$ $(0.81 \mathrm{~g}), \mathbf{2 d}(0.87 \mathrm{~g}), 2 \mathrm{e}(0.95 \mathrm{~g}), 2 \mathrm{f}(1.0 \mathrm{~g}), \mathbf{2 g}(0.74 \mathrm{~g})$, and $2 \mathrm{~h}(0.79 \mathrm{~g})$, respectively.

General procedure for the synthesis of 1,3,4-oxadiazole-2-thiones (5a-h). - Hydrazide 3 $(10.30 \mathrm{mmol})$ was added to a stirred solution of $\mathrm{KOH}(12.37 \mathrm{mmol})$ in $\mathrm{MeOH}(30 \mathrm{~mL})$, followed by addition of $\mathrm{CS}_{2}(0.75 \mathrm{~mL}, 12.37 \mathrm{mmol})$ dropwise under stirring. The obtained yellow solution was heated under reflux till the evolution of $\mathrm{H}_{2} \mathrm{~S}$ ceased (18-20 h). After cooling, the solution was filtered, and the filtrate was poured into ice-cooled water and acidified with $6 \mathrm{~mol} \mathrm{~L}^{-1} \mathrm{HCl}$ to $\mathrm{pH} 3-4$. The precipitated solid was filtered, dried and recrystallized from aq. EtOH to afford pure oxadiazoles.

5-[1-(4-Bromophenoxy)ethyl]-1,3,4-oxadiazole-2-thione (5a), 5-[1-(4-bromophenoxy) propyl]-1,3,4-oxadiazole-2-thione (5b), 5-[1-(4-chlorophenoxy)ethyl]-1,3,4-oxadiazole-2- -thione (5c), 5-[1-(4-chlorophenoxy)propyl]-1,3,4-oxadiazole-2-thione (5d), 5-[1-(3,4-dichlorophenoxy)ethyl]-1,3,4-oxadiazole-2-thione (5e), 5-[1-(3,4-dichlorophenoxy)propyl]-1,3,4-oxadiazole-2-thione (5f), 5-[1-(4-methylphenoxy)etyl]-1,3,4-oxadiazole-2-thione (5g) and 5-[1-(4-methylphenoxy)propyl]-1,3,4-oxadiazole-2-thione $(5 \mathbf{h})$ were prepared from $3 \mathbf{a}$ $(2.67 \mathrm{~g}), 3 \mathrm{~b}(2.81 \mathrm{~g}), 3 \mathrm{c}(2.21 \mathrm{~g}), 3 \mathrm{~d}(2.36 \mathrm{~g}), 3 \mathrm{e}(2.56 \mathrm{~g}), 3 \mathrm{f}(2.71 \mathrm{~g}), 3 \mathrm{~g}(2.00 \mathrm{~g})$, and $3 \mathrm{~h}$ $(2.14 \mathrm{~g})$, respectively.

General procedure for the synthesis of N-(benzothiazol-2-yl)-2-(5-(1-(4- or 3,4-halo- or alkylphenoxy)ethyl)-1,3,4-oxadiazole-2-yl-thio)acetamides (6a-h). - To a solution of 5 (0.95 mmol) in acetone $(40 \mathrm{~mL})$, benzothiazolyl chloroacetamide $(4)(1.05 \mathrm{mmol})$ and anhydrous $\mathrm{K}_{2} \mathrm{CO}_{3}(3.81 \mathrm{mmol})$ were added and the mixture was stirred at $23^{\circ} \mathrm{C}$ for $5 \mathrm{~h}$. The resulting reddish solution was heated under reflux till completion of the reaction. After cooli$\mathrm{ng}$, the reaction mixture was filtered and the filtrate was concentrated to $10 \mathrm{~mL}$, followed by addition of cold water. The resulting solid was filtered, dissolved in acetone and boiled with decolorizing charcoal. The charcoal was filtered and the filtrate was evaporated to dryness to afford pure benzothiazole derivatives 6a-h.

$N$-(Benzothiazol-2-yl)-2-\{5-[1-(4-bromophenoxy)ethyl]-1,3,4-oxadiazole-2-yl-thio\}acetamide (6a), $N$-(benzothiazol-2-yl)-2-\{5-[1-(4-bromophenoxy)propyl]-1,3,4-oxadiazole-2- 
T. Akhtar et al.: In vitro antitumor and antiviral activities of new benzothiazole and 1,3,4-oxadiazole-2-thione derivatives, Acta Pharm. 58 (2008) 135-149.

-yl-thio\}acetamide (6b), N-(benzothiazol-2-yl)-2-\{5-[1-(4-chlorophenoxy)ethyl]-1,3,4-oxadiazole-2-yl-thio\}acetamide (6c), N-(benzothiazol-2-yl)-2-\{5-[1-(4-chlorophenoxy)propyl] -1,3,4-oxadiazole-2-yl-thio\}acetamide (6d), N-(benzothiazol-2-yl)-2-\{5-[1-(3,4-dichlorophenoxy)ethyl]-1,3,4-oxadiazole-2-yl-thio\}acetamide (6e), N-(benzothiazol-2-yl)-2-\{5-[1-(3,4-dichlorophenoxy)propyl]-1,3,4-oxadiazole-2-yl-thio\}acetamide (6f), N-(benzothiazol-2-yl)-2-\{5-[1-(4-methylphenoxy)ethyl]-1,3,4-oxadiazole-2-yl-thio\}acetamide (6g) and $\mathrm{N}$ -(benzothiazol-2-yl)-2-\{5-[1-(4-methylphenoxy)propyl]-1,3,4-oxadiazole-2-yl-thio\}acetamide (6h) were prepared from $5 \mathrm{a}(2.85 \mathrm{~g}), 5 \mathrm{~b}(2.99 \mathrm{~g}), 5 \mathrm{c}(2.44 \mathrm{~g}), 5 \mathrm{~d}(2.57 \mathrm{~g}), 5 \mathrm{e}(2.76 \mathrm{~g}), \mathbf{5 f}$ $(2.90 \mathrm{~g}), 5 \mathrm{~g}(2.44 \mathrm{~g})$, and $5 \mathrm{~h}(2.38 \mathrm{~g})$, respectively.

\section{BIOLOGICAL ASSAYS}

Cells and viruses. - Cell lines were purchased from the American Type Culture Collection (ATCC) (USA). The absence of mycoplasma contamination was checked periodically by the Hoechst staining method. Cell lines supporting the multiplication of RNA viruses were: $\mathrm{CD}^{+}$human T-cells containing an integrated HTLV-1 genome (MT-4), Madin Darby Bovine Kidney (MDBK), Baby Hamster Kidney (BHK-21) and Monkey Kidney (Vero 76) cells.

In vitro antitumor activity. - Compounds $5 \mathbf{a}-\mathbf{h}$ and $\mathbf{6 a}-\mathbf{h}$ were tested in vitro against a panel of tumor cell lines consisting of CD4 human T-cells containing an integrated leukaemia (CCRF-CEM), human acute T-lymphoblastic leukaemia (WIL-2NS), human splenic B-lymphoblastoid cells (CCRF-SB), human acute B-lymphoblastic leukaemia (SK-MEL-28), human skin melanoma (SK-MEL-28), human breast adenocarcinoma (MCF-7), human lung squamous carcinoma (SK-MES-1), human hepatocellular carcinoma (HepG2), human prostate carcinoma (DU-145), human foreskin fibroblast (CRL7065) and human lung fibroblast (MRC-5). The Microculture Tetrazolium Assay (MTT) method (16) was used for estimation of the in vitro tumor-inhibiting activity of the tested compounds. The cell lines of tumor subpanels were incubated within five concentrations (0.01-100 $\mu \mathrm{mol} \mathrm{L}-1$ ) of each tested compound for $48 \mathrm{~h}$. The results are displayed in Table III.

Compounds were dissolved in DMSO at $100 \mathrm{mmol} \mathrm{L}^{-1}$ and then diluted in culture medium.

Cytotoxicity assays. - For cytotoxicity tests, run in parallel with antiviral assays, MDBK and BHK cells were resuspended in 96 multiwell plates at an initial density of $6 \times$ $10^{5}$ and $1 \times 10^{6}$ cells $\mathrm{mL}^{-1}$, respectively, in maintenance medium, without or with serial dilutions of test compounds. Cell viability was determined after $48-96 \mathrm{~h}$ at $37^{\circ} \mathrm{C}$ in a humidified $\mathrm{CO}_{2}(5 \%)$ atmosphere by the 3-tetrazolium bromide method (MTT). Vero 76 cells were resuspended in 24 multiwell plates at an initial density of $4 \times 10^{5}$ cells $^{\mathrm{mL}^{-1}}$. The cell number of Vero 76 monolayer was determined by staining with the crystal violet dye. For cytotoxicity evaluations, exponentially growing cells derived from human haematological tumors [CD4 ${ }^{+}$human T-cells containing an integrated HTLV- 1 genome (MT-4)] were seeded at an initial density of $1 \times 10^{5}$ cells $\mathrm{mL}^{-1}$ in 96 well plates in RPMI-1640 medium supplemented with 10\% faetal calf serum (FCS), 100 units $\mathrm{mL}^{-1}$ penicillin $\mathrm{G}$ and $100 \mu \mathrm{g} \mathrm{mL}-1$ streptomycin. Cell cultures were then incubated at $37^{\circ} \mathrm{C}$ in a humidi- 
fied, $5 \% \mathrm{CO}_{2}$ atmosphere in the absence or presence of serial dilutions of the test compounds. Cell viability was determined after $96 \mathrm{~h}$ at $37^{\circ} \mathrm{C}$ by the MTT method.

In vitro antiviral activity. - Compounds 5a-h and $6 \mathbf{a}-\mathbf{h}$ were tested for their anti-HIV-1 activity in vitro, using IIIB strain in human T-lymphocyte (MT-4) cells, based on a MTT assay. Compounds $\mathbf{5 a - h}$ and $\mathbf{6 a}-\mathbf{h}$ were also evaluated against various viruses: mock-infected MDBK (bovine normal kidney), BVDV (bovine viral diarrhea virus), mock-infected BHK (hamster normal kidney fibroblast), BHK (kidney fibroblast) cells from the YFV (yellow fever virus) and Reo (reovirus 1), mock-infected VERO-76 (monkey normal kidney), HSV-1 (herpesvirus 1), VV (vaccinia virus), VSV (vesicular stomatitis virus), CVB-2 (coxsackievirus B2), Sb-1(poliovirus 1) and RSV (respiratory syncytial virus) by $50 \%$ in VERO-76 monolayers.

Antiviral assays. - Activity of compounds against the Human Immunodeficiency virus type-1 (HIV-1) was based on inhibition of virus-induced cytopathogenicity in MT-4 cells acutely infected with a multiplicity of infection (m.o.i.) of 0.01 . Thus, $50 \mu \mathrm{L}$ of RPMI containing $1 \times 10^{4}$ MT- 4 was added to each well of flat-bottom microtitre trays containing $50 \mu \mathrm{L}$ of RPMI, without or with serial dilutions of test compounds. Then, $20 \mu \mathrm{L}$ of an HIV-1 suspension containing $100 C_{50}$ (CCID - cell culture infectious dose $50 \%$ ) was added. After a 4-day incubation, cell viability was determined by the MTT method. Activity of compounds against the Yellow fever virus (YFV) and Reo virus type-1 (Reo-1) was based on inhibition of virus-induced cytopathogenicity in acutely infected BHK-21 cells. Activities against the Bovine viral diarrhoea virus (BVDV), in infected MDBK cells, were also based on inhibition of virus-induced cytopathogenicity.

BHK and MDBK cells were seeded in 96-weels plates at a density of $5 \times 10^{4}$ and $3 \times$ $10^{4}$ cells / well, respectively, and were allowed to form confluent monolayers by incubating overnight in growth medium at $37{ }^{\circ} \mathrm{C}$ in a humidified $\mathrm{CO}_{2}(5 \%)$ atmosphere. Cell monolayers were then infected with $50 \mu \mathrm{L}$ of a proper virus dilution (in serum-free medium) to give an m.o.i. $=0.01 ; 1 \mathrm{~h}$ later, $50 \mu \mathrm{L}$ of MEM Earle's medium, supplemented with inactivated foetal calf serum (FCS), $1 \%$ final concentration, without or with serial dilutions of test compounds, was added. After $3-4$ days incubation at $37^{\circ} \mathrm{C}$, cell viability was determined by the MTT method.

Activity of compounds against the Coxsackie virus, B-2 strain (CVB-2), Polio virus type-1 (Polio-1), Sabin strain, and Vesicular Stomatitis Virus (VSV), Vaccinia Virus (VV), Herpes Virus 1 (HSV-1) and Respiratory syncytial virus (RSV), A-2 strain, in infected Vero 76 cells, was determined by plaque reduction assays in Vero 76 cell monolayers. To this end, Vero 76 cells were seeded in 24 -well plates at a density of $2 \times 10^{5}$ cells/well and allowed to form confluent monolayers by incubating overnight ingrowth medium at 37 ${ }^{\circ} \mathrm{C}$ in a humidified $\mathrm{CO}_{2}(5 \%)$ atmosphere. Then, monolayers were infected with $250 \mu \mathrm{L}$ of proper virus dilutions to give 50-100 PFU/well. Following removal of unadsorbed virus, $500 \mu \mathrm{L}$ of Dulbecco's modified Eagle's medium supplemented with $1 \%$ inactivated FCS and $0.75 \%$ methyl cellulose, without or with serial dilutions of test compounds, was added. Cultures were incubated at $37^{\circ} \mathrm{C}$ for 2 (Sb-1 and VSV), 3 (CVB-2, VV and HSV-1) or 5 days (RSV) and then fixed with PBS containing 50\% EtOH and $0.8 \%$ crystal violet, washed and air-dried. Plaques were then counted, $50 \%$ effective concentration $\left(E C_{50}\right)$ was calculated by the linear regression technique. 


\section{RESULTS AND DISCUSSION}

Commercial substituted phenols were selected as starting precursors for the synthesis of oxadiazoles $\mathbf{5 a}-\mathbf{h}$. The substituted phenols were converted into the corresponding phenoxy acids 1a-h, prepared previously in our laboratory, by the reaction with 2-bromoalkanoic acids in aqueous solution of $\mathrm{NaOH}(14)$, followed by Fischer esterfication (15) in acidic $\mathrm{MeOH}$ to give the esters $\mathbf{2 a - h}$. Compounds $\mathbf{2 a - h}$ were used directly for the next step without further purification. Treatment of $2 \mathrm{a}-\mathrm{h}$ with hydrazine hydrate afforded the corresponding hydrazides $3 \mathbf{a}-\mathbf{h}$, which gave the 1,3,4-oxadiazole-2-thione/ thiol derivatives $\mathbf{5 a - h}$ on treatment with $\mathrm{CS}_{2}$ and $\mathrm{KOH}$ in $\mathrm{MeOH}$. The structures of $\mathbf{3 a}-\mathbf{h}$ were comfirmed by the ${ }^{1} \mathrm{H}-,{ }^{13} \mathrm{C}$ NMR and mass spectra. The cyclization of $3 \mathbf{a}-\mathbf{h}$ to $1,3,4-$ -oxadiazole-2-thiones (5a-h) was followed by the ${ }^{1} \mathrm{H}$ NMR spectra where the three $\mathrm{NH}$ protons of hydrazides disappeared on the expense of the appearance of broad singlets in the region $\delta$ 9.91-11.62 ppm, attributed to $\mathrm{NH}$ in $\mathbf{5 a}, \mathbf{5 b}, \mathbf{5 d}, \mathbf{5 g}$ and $\mathbf{5 h}$. In the case of compounds $5 \mathbf{c}, 5 \mathbf{e}$ and $5 \mathbf{f}$, the ${ }^{1} \mathrm{H}$ NMR spectra were characterized by the presence of $\mathrm{SH}$ signal at $\delta 1.27 \mathrm{ppm}$; meanwhile, ${ }^{13} \mathrm{C}$ NMR spectra exhibited signals at $\delta \sim 178.5 \mathrm{ppm}$, attributed to the $\mathrm{C}=\mathrm{S}$ carbons, and then supporting the existence of these compounds in the tautomeric form. The signals in the range of $\delta 161.6-163.2 \mathrm{ppm}$ were attributed to $\mathrm{C}=\mathrm{N}$ of the 1,3,4-oxadiazole-2-thiones. The mass spectral data were consistent with the structures of the synthesized compounds $5 \mathbf{a}-\mathbf{h}$.

The key intermediate 4 , which was used for coupling of compounds 5 a-h with benzothiazole, was prepared by the reaction of chloroacetyl chloride with 2-aminobenzothiazole (17). The benzothiazole derivatives $6 \mathrm{a}-\mathrm{h}$ were obtained by condensation of 4 with compounds $\mathbf{5 a}-\mathbf{h}$, using anhydrous $\mathrm{K}_{2} \mathrm{CO}_{3}$ in acetone. The structures of $\mathbf{6 a - h}$ were confirmed by IR, ${ }^{1} \mathrm{H}-,{ }^{13} \mathrm{C}$ NMR and mass spectra. The ${ }^{1} \mathrm{H}$ NMR spectra exhibited additional signals in the aromatic region, in addition to a singlet for $\mathrm{SCH}_{2}$ protons of the acetamide part in the region $\delta 4.42-4.63 \mathrm{ppm}$. The signal for $\mathrm{SCH}_{2}$ carbon was oriented in the ${ }^{13} \mathrm{C}$ NMR spectra in the region $\delta 35.9-36.2 \mathrm{ppm}$. The mass fragmentation patterns were consistent with the suggested structures; however, the FABMAS spectra showed the protonated molecular ions of these compounds.

Cytotoxicity was measured on MT-4 cells. None of the in vitro tested compounds were found to inhibit HIV-replication, at $E C_{50}$ lower than the $C C_{50}$, compared to the antiviral agent efavirenz (EFV) (18). Thus, no selective anti-HIV activity could be witnessed $\left(E C_{50}>100 \mu \mathrm{g} \mathrm{mL}^{-1}\right)$. As compared to the known antiviral agent Cidofovir (19), no activity was found for any of the compounds at non-toxic concentrations.

Compounds $6 \mathrm{~d}$ and $6 \mathrm{e}$ were found to be the prominent cytotoxic and selective ones toward leukaemia cell lines CCRF-CEM with $C_{50} 12 \pm 2$, and $8 \pm 1 \mu \mathrm{g} \mathrm{mL}^{-1}$, respectively. In comparison with the antitumor agent doxorubicin (20) as a control, all the tested analogues 6a-h were inactive against the other ten cancer cells lines with $C C_{50} 100 \mu \mathrm{g} \mathrm{mL}^{-1}$.

The metabolic biotransformation of $6 \mathrm{~d}$ and $6 \mathrm{e}$ in human cells might be mediated through the CYP1 family of cytochrome P450s (21).

Comparison of the activities of compounds $6 \mathbf{a}$ to $\mathbf{6 h}$ showed that the inclusion of the two chloro substituents in the $3^{\prime}, 4^{\prime}$-positions (compound 6e) shifted the threshold of potency from the inactive side toward activity, particularly against the CD4+ human acute T-lymphoblastic leukaemia cell line (CCRF-CEM) $\left(C_{50}=8 \pm 1 \mu \mathrm{g} \mathrm{mL}^{-1}\right)$. The acti- 
T. Akhtar et al.: In vitro antitumor and antiviral activities of new benzothiazole and 1,3,4-oxadiazole-2-thione derivatives, Acta Pharm. 58 (2008) $135-149$

Table III. Antitumor activity in most sensitive tumor cell lines

\begin{tabular}{ccccc}
\hline \multicolumn{5}{c}{$\mathrm{CC}_{50}\left(\mu \mathrm{g} \mathrm{mL}^{-1}\right)^{\mathrm{a}}$} \\
\hline Compd. & MT-4 & CCRF-CEM $^{\mathrm{b}} \mathrm{f}$ & WIL-2NS $^{\mathrm{d}, \mathrm{f}}$ & CCRF-SB $^{\mathrm{e}, \mathrm{f}}$ \\
\hline $\mathbf{6 a}$ & 100 & $18 \pm 4$ & 100 & $>100$ \\
$\mathbf{6 b}$ & $>100$ & $14 \pm 3$ & $>100$ & $>100$ \\
$\mathbf{6 c}$ & $>100$ & $12 \pm 2$ & $>100$ & $>100$ \\
$\mathbf{6 d}$ & $>100$ & $8 \pm 1$ & $46 \pm 5$ & $>100$ \\
$\mathbf{6 e}$ & $>100$ & $15 \pm 0.7$ & $14 \pm 0.7$ & $>100$ \\
$\mathbf{6 f}$ & $>100$ & $17 \pm 0.2$ & $58 \pm 5$ & $>100$ \\
$\mathbf{6 g}$ & $>100$ & $19 \pm 2$ & $64 \pm 2$ & $83 \pm 18$ \\
$\mathbf{6 h}$ & $>100$ & 0.02 & $40 \pm 7$ & $>100$ \\
Doxorubicing & 0.01 & & 0.02 & 0.03 \\
\hline
\end{tabular}

a Compound concentration required to reduce cell proliferation by $50 \%$, as determined by the MTT method, under conditions allowing untreated controls to undergo at least three consecutive rounds of multiplication. ${ }^{\mathrm{b}} \mathrm{CD} 4^{+}$human T-cells containing an integrated HTLV-1.

${ }^{c} \mathrm{CD}^{+}$human acute T-lymphoblastic leukaemia.

d Human splenic B-lymphoblastoid cells.

e Human acute B-lymphoblastic leukaemia.

${ }^{\mathrm{f}}$ Average $\pm \mathrm{SD}, n=2$.

g Control.

vity was decreased by structural changes with a single chloro substituent (e.g., in compound $\left.6 \mathrm{~d} C C_{50}=12 \pm 2 \mu \mathrm{g} \mathrm{mL}-1\right)$. On the other hand, upon replacement of the chloro substituent of $\mathbf{6 d}$ or $\mathbf{6 e}$ with a bromo substituent $(\mathbf{6 b})$, a slight decrease in leukaemia inhibitory activity $\left(C_{50}=14 \pm 3 \mu \mathrm{g} \mathrm{mL} \mathrm{m}^{-1}\right)$ was observed.

\section{CONCLUSION}

In summary, in vitro screen led to identification of compound $6 \mathbf{e}$ ( $N$-(benzothiazol-2-yl)-2-\{5-[1-(3,4-dichlorophenoxy)ethyl]-1,3,4-oxadiazole-2-yl-thio\}acetamide) as a new antitumor candidate, being the promising agent for further structural modification, and pharmacological evaluation.

\section{REFERENCES}

1. D. Shi, T. D. Bradshaw, S. Wrigley, C. J. McCall, P. Lelieveld, I. Fichtner and M. F. G. Stevens, Antitumor benzothiazoles. 3. Synthesis of 2-(4-aminophenyl)benzothiazoles and evaluation of their activities against breast cancer cell lines in vitro and in vivo, J. Med. Chem. 39 (1996) 33753384; DOI:10.1021/jm9600959. 
2. T. D. Bradshaw, S. Wrigley, R. J. Schultz, K. D. Paull and M. F. G. Stevens, 2-(4-Aminophenyl) benzothiazoles: novel agents with selective profiles of in vitro antitumor activity, Br. J. Cancer 77 (1998) 745-752.

3. A. Rana, N. Siddiqui and S. A. Khan, Benzothiazoles: a new profile of biological activities, Indian J. Pharm Sci. 69 (2007) 10-17.

4. G. Trapani, M. Franco, A. Latrofa, A. Reho and G. Liso, Synthesis, in vitro and in vivo cytotoxicity, and prediction of the intestinal absorption of substituted 2-ethoxycarbonyl-imidazo[2,1- $b]$ benzothiazoles, Eur. J. Pharm. Sci. 14 (2001) 209-216; DOI: 10.1016/S0928-0987(01)00173-7.

5. K. J. Watson, D. R. Anderson and S. T. Nguyen, Toward polymeric anticancer drug cocktails from ring-opening metathesis polymerization, Macromolecules 34 (2001) 3507-3509; DOI:10.1016/ S0928-0987(01)00173-7.

6. I. Caleta, M. Grdisa, D. Mrvos-Sermek, M. Cetina, V. K. Tralić-Kulenović, G. Pavelić and G. Karminski-Zamola, Synthesis, crystal structure and antiproliferative evaluation of some new substituted benzothiazoles and styrylbenzothiazoles, Farmaco 59 (2004) 297-305; DOI: 10.1016/ j.farmac.2004.01.008.

7. A. I. Loaiza-Pérez, V. Trapni, V. Patel, C. Hose, S. S. Singh, J. B. Trepel, M. F. G. Stevens, T. D. Bradshaw and E. A. Sauville, The aryl hydrocarbons receptor mediates sensitivity of MCF-7 breast cancer cells to the antitumor agent 2-(4-amino-3-methylphenyl) benzothiazole, Mol. Pharmacol. 61 (2002) 13-19.

8. V. Trapani, V. Patel, C.-O. Leong, H. P. Ciolino, G. C. Yeh, C. Hose, J. B. Trepel, M. F. G. Stevens, E. A. Sausville and A. I. Loaiza-Pérez, DNA damage and cell cycle arrest induced by 2-(4-amino-3-methylphenyl)-5-fluorobenzothiazole (5F 203, NSC 703786) is attenuated in aryl hydrocarbon receptor deficient MCF-7 cells, Br. J. Cancer 88 (2003) 599-605; DOI:10.1038/sj.bjc.6600722

9. G. Mortimer, G. Wells, J.-P. Grochard, E. L. Stone, T. D. Bradshaw, M. F. G. Stevens and A. D. Westwell, Antitumor benzothiazoles. 26. 2-(3,4-dimethoxyphenyl)-5-fluoro benzothiazole (GW 610, NSC 721648), a simple fluorinated 2-arylbenzothiazole, shows potents and selective inhibitory activity against lung, colon, and breast cancer cell lines, J. Med. Chem. 49 (2006) 179-185; DOI: $10.1021 / \mathrm{jm} 050942 \mathrm{k}$.

10. G. Wells, J. M. Berry, T. D. Bradshaw, A. M. Burger, A. Seaton, B. Wang, A. D. Westwell and M. F. G. Stevens, Substituted -4-hydroxycyclohexa-2,5-dien-1-ones with selective activities against colon and renal cancer cell lines, J. Med. Chem. 46 (2003) 532-541; DOI:10.1021/jm020984y.

11. T. D. Bradshaw and A. D. Westwell, The development of the antitumor benzothiazole prodrug, Phortress, as a clinical candidate, Curr. Med. Chem. 11 (2004) 1009-1021.

12. M. Yoshida, I. Hayakawa, N. Hayashi, T. Agatsuma, Y. Oda, F. Tanzawa, S. Iwasaki, K. Koyama, H. Furukawa, S. Kurakata and Y. Sugano, Synthesis and biological evaluation of benzothiazole derivatives as potent antitumor agents, Bioorg. Med. Chem. Lett. 15 (2005) 3328-3333; DOI:10. 1016/j.bmcl.2005.05.077.

13. I. Hutchinson, T. D. Bradshaw, C. S. Matthews, M. F. G. Stevens and A. D. Westwell, Antitumour benzothiazoles. Part 20: 3'-cyano and 3'-alkynyl-substituted 2-(4'-aminophenyl)benzothiazoles as new potent and selective analogues, Bioorg. Med. Chem. Lett. 13 (2003) 471-474; DOI: 10.1016/S0960-894X(02)00930-7.

14. T. Akhtar, M. K. Rauf, M. Ebihara and S. Hameed, 2-(3,4-Dichlorophenoxy)propionic acid. Acta Cryst. E63 (2007) 2590-2592; DOI: 10.1107/S1600536807014249.

15. R. Moumne, S. Lavielle and P. Karoyan, Efficient synthesis of 2-amino acid by homologation of $\beta^{2}$-amino acids involving the reformatsky reaction and mannich-type imminium electrophile, $J$. Org. Chem. 71 (2006) 3332-3334; DOI: 10.1021/jo060316a.

16. M. C. Alley, D. A. Scudiero, A. Monks, M. L. Hursey, M. J. Czerwinski, D. L. Fine, B. J. Abbott, L. G. Mayo, R. H. Schoemaker and M. R. Boyd, Feasibility of drug screening with panels of human tumor cell lines using a microculture tetrazolium assay, Cancer Res. 48 (1988) 589-601. 
17. G. Yang, L. Xu, and A. Lu, Synthesis and bioactivity of novel triazolo [1,5-a]pyrimidine derivatives, Heteroatom Chem. 12 (2001) 491-498; DOI: 10.1002/hc.1075.

18. S. D. Young, S. F. Britcher, L. O. Tran, L. S. Payne, W. C. Lumma, T. A. Lyle, J. R. Huff, P. S. Anderson, D. B. Olsen, S. S. Carroll, D. J. Pettibone, J. A. Obrien, R. G. Ball, S. K. Balani, J. H. Lin, I. W. Chen, W. A. Schleif, V. V. Sardana, W. J. Long, V. W. Byrnes and E. A. Emini, Novel, highly potent non-nucleoside inhibitor of the human immunodeficiency-virus type-1 reverse transcriptase, Antimicrob. Agents Chemother. 39 (1995) 2602-2605.

19. E. De Clercq, Clinical potential of the acyclic nucleoside phosphonates cidofovir, adefovir, and tenofovir in treatment of DNA virus and retrovirus infections, Clin. Microbiol. Rev. 16 (2003) 569-596; DOI: 10.1128/CMR.16.4.

20. R. B. Weiss, The anthracyclines: will we never find a better docorubicin, 19 (1992) 670-686.

21. C. D. Hose, M. Hollingshead, E. A. Sauville and A. Monks, Induction of CYP1A1 in tumor cells by the antitumor agent 2-[4-amino-3-methylphenyl]-5-fluoro-benzothizole: A potential surrogate marker for patient sensitivity, Mol. Cancer Ther. 2 (2003) 1265-1272.

\section{$S A \check{Z} E T A K$}

\section{In vitro antitumorsko $\mathrm{i}$ antivirusno djelovanje novih benzotiazola i 1,3,4-oksadiazol-2-tion derivata}

TASHFEEN AKHTAR, SHAHID HAMEED, NAJIM A. AL-MASOUDI, ROBERTA LODDO i PAOLO LA COLLA

U pet reakcijskih koraka sintetizirana je serija novih derivata benzotiazola $6 a-h$ polazeći iz supstituiranih fenola preko 1,3,4-oksadiazol-2-tiona 5a-h. Sintetizirani spojevi ispitani su na antitumorsko djelovanje. Benzotiazol derivati $6 \mathrm{~d}$ i 6 e pokazali su jak učinak na staničnu liniju leukemije CCRF-CEM $\left(C_{50}=12 \pm 2\right.$, odnosno $\left.8 \pm 1 \mu \mathrm{mol} \mathrm{L}^{-1}\right)$. Ti su spojevi predvodni spojevi za daljnji razvoj. Nadalje, novi su spojevi testirani na djelovanje na nekoliko tipova virusa koji sadrže bilo pozitivni (ssRNA+) bilo negativni (RNA-) jednolančani RNA genom ili dvolančani RNA genom (dsRNA), te na neke Flaviviridae viruse.

Ključne riječi: 1,3,4-oksatiazoli, supstituirani benzotiazoli, antitumorsko djelovanje, antivirusno djelovanje

Department of Chemistry, Quaid-I-Azam University, Islamabad-45320, Pakistan

Fachbereich Chemie, Universität Konstanz, Postfach 5560, D-78457 Konstanz, Germany (formerly)

Department of Biomedical Sciences and Technologies, University of Cagliari, Cittadella Universitaria 09042 Monserrato (CA), Italy 